\title{
FOOD INDICATORS AND THEIR RELATIONSHIP WITH 10 TO 12 YEAR-OLDS' PERSONAL WELL-BEING
}

\author{
ABSTRACT \\ This study aimed to test subjective indicators designed to analyze the role food plays in \\ children's lives, explore children's personal well-being, and evaluate the relationship between \\ these two phenomena. It was conducted on 371 children aged 10 to 12 by means of a self- \\ administered questionnaire.
}

Results showed a marked interest in food on the part of children, who consider taste and health the most important indicators when it comes to eating. They demonstrated a high level of personal well-being, measured using Cummins \& Lau's adapted version of the Personal WellBeing Index-School Children (PWI-SC) (2005), overall life satisfaction (OLS) and satisfaction with various life domains (friends, family, sports, food and body).

Regression models were conducted to explain satisfaction with food, taking as independent variables the interest children have in food, the importance they give to different reasons for eating, scores from the PWI-SC, OLS and satisfaction with various life domains. In the final model, it was found that OLS, health indicators, satisfaction with health from the PWI-SC and satisfaction with your body contribute to explaining satisfaction with food.

The results obtained suggest that satisfaction with food is a relevant indicator in the exploration of children's subjective well-being, calling into question the widespread belief that these aspects are of exclusive interest to adults. They also seem to reinforce the importance of including food indicators in any study aimed at exploring the well-being of the 10 to 12 year-old population.

KEY WORDS: Personal well-being, subjective children, subjective indicators, satisfaction with food. 
INTRODUCTION

The scientific community first began to take an interest in the relationship between food and health in the 1950s, a decade that saw the discovery of the link between certain eating habits and a decreased risk of arteriosclerosis. Besides being a nutritional process, eating has significant connotations relating to pleasure, and indeed serves as an element of social, cultural and religious identification all at once. It also promotes and intervenes in the establishment of interpersonal and emotional relationships that ultimately shape individuals' eating habits, thereby having a bearing on their long-term health (Government of Catalonia's Department of Health 2005).

Food is also one of the key exogenous factors that affect children's proper growth and development (Aranceta et al. 2004). This highlights the importance of addressing the issue of food from an early age. Children grow and change quickly during their school years, with the period between the ages of 6 and 12 representing one of the most important for the development of their cognitive, physical and social skills. Although children begin to develop causal reasoning during this stage, the criteria that affect their choice of food remain rather immediate. That said, children at this age do start to take an interest in the links between food and health (Contento 2007). Furthermore, they display an increasing amount of independence, leading to the expansion of their relationships and a heightened capacity to make decisions (Aranceta 1995), some of which may revolve around aspects relating to food.

Research conducted on child nutrition in recent years (Serra et al. 2002; Contento et al. 2007, among others) has demonstrated a need to deal with this issue, in part due to the dietary imbalance and health issues in evidence among the child population. Studies have also been carried out to analyze eating habits and satisfaction in relation to food received in specific contexts (in schools, hospitals, etc.). However, these largely focus on an assessment of the service received and the nutritional quality of the menus served (Watters et al. 2003; Mavrommatis et al. 2011) and fail to take into account the possible role of food in children's subjective well-being and how it relates to their opinions, perceptions and evaluations. 
This article argues that in order to understand individuals' eating habits and the role that food plays in their lives one must go beyond strictly dietary and nutritional indicators for different foods and consider a range of possible psychosocial indicators. These indicators concern the immediate context in which food is consumed (eating habits in the family home and environmental aspects of food, relationships with dining companions), a wider social context (the importance given to food, beliefs about particular foods, the application of regulations on dietary matters) and a more individual dimension: each person's judgments with respect to different aspects of life, including subjective well-being and personal food preferences.

This study will focus on some aspects of the last of the aforementioned areas using "satisfaction with food" as an intersection indicator between these two phenomena. When we talk about satisfaction with food, we refer to the evaluation of those aspects that can help children enjoy their food and lead them to consider it a pleasurable and important element for their well-being and quality of life.

Subjective well-being is generally held to be a multidimensional assessment reflecting the combination of a cognitive process (satisfaction with life both as a whole and in relation to various specific domains: health, school, family, friends and relationships with other people, among others) with two affective processes (presence of positive affect and absence of negative affect) (Argyle 1987; Diener 1984; Diener \& Larsen 1993; quoted in Eid \& Diener 2004). This study focuses on the more cognitive side of well-being, leaving an analysis of the more affective aspects for future research.

Major contributions to the study of subjective well-being have been made by Cummins (1998; 2003), who argues for the inclusion of various domains when it comes to analyzing the judgments that people make about their lives when questioned about their personal wellbeing. He also contends that measuring the variable of overall life satisfaction involves a homeostatic control mechanism, similar to the way in which blood pressure is measured, but psychological. This means that the range of variation in personal well-being scores recorded among people from the same country and between different countries tends to be limited, pointing to the existence of normative values for well-being. 
Cummins et al. (2003) have developed a tool to investigate subjective well-being, which they called the Personal Well-being Index (PWI). It assesses responses regarding level of satisfaction in the following domains: standard of living, personal health, life achievement, personal relationships, personal safety, community-connectedness, future security, and spirituality and religion. It also includes satisfaction with life as a whole. Various versions of this index have been designed to meet the specific needs of different age groups: adults (PWI-A) (Cummins \& Lau 2006), school children (PWI-SC) (Cummins \& Lau 2005) and pre-school children (PWI-PS) (Cummins \& Lau 2004).

In light of the above, the aims of this study are: (1) to test indicators designed to analyze the role food plays in the lives of children aged between 10 and 12, (2) to test indicators that allow assessment of their personal well-being, (3) to study potential links between the two phenomena, taking satisfaction with food as a departure point, and (4) to explore the different patterns displayed by participants in relation to these indicators according to gender. 


\section{METHOD}

The data analyzed in this study were collected within the context of a larger research study on school food carried out in 2008 in the region of Osona (Catalonia, north-east Spain), which was funded by the Government of Catalonia's Department of Health and the University of Vic. Of the 79 schools in the region, 26 (32.9\%) expressed an interest in participating. The target population of this study was recruited from 18 of these schools. Eight schools were excluded because they did not include primary-age students; another school with a special education programme serving intellectually-impaired children was also excluded.

In light of the fact that the data analyzed in this article are extracted from a school dining-room study, it is clear that participating children are all regular users of school-provided food services.

\section{Sample}

Data are taken from a total of 371 children in the region of Osona in their last two years of primary school (students were between 10 and 12 years of age). This sample comprises $25.82 \%$ of all children enrolled in the last two years of primary school in the 18 participating schools. This age group was selected for two reasons: the difficulty of assessing the well-being of children under 10 , and the fact that other studies have reflected a growing interest in dietary issues for children in this cohort.

The majority of participating schools were state schools $(77.8 \%$, mirroring the total distribution of state schools in the region), while the remainder of participating entities were publicly-funded private schools from the region (22.2\%). Half of these schools $(50 \%)$ were located in semi-rural areas (with populations between 2,000 and 5,000 residents), while $33.3 \%$ were in urban areas (with more than 5,000 residents) and $16.6 \%$ of schools were in rural areas (with less than 2,000 residents).

$53.6 \%$ of the students were male $(n=199)$ and $46.6 \%$ were female $(n=172)$. The mean age of these students was 10.73 years old $(S D=0.65) .38 .5 \%$ of students were 10 years old $(21 \%$ 
boys and $17.5 \%$ girls), $50.1 \%$ were 11 (26.7\% boys and $23.4 \%$ girls), and the remaining $11.4 \%$ were $12(5.4 \%$ boys and $6 \%$ girls).

Instruments

Data were collected using a questionnaire designed specifically for this study and containing the following scales:

- One item regarding children's global interest in food scored on an 11-point scale, with 0 representing not interested at all and 10 representing extremely interested.

- A group of items evaluated the importance attributed to various eating-related topics: "this food is good for my health," "this food tastes good," "this food is easy to eat," "this food is well-known," "someone recommended this food to me," "my friends also eat this food," "my parents want me to eat this", "I have seen the food on TV", "I have enough time to eat", "my body needs this food," and, finally, "I feel good after eating this food" (scored from $0=$ not at all to $10=$ very much).

- $\quad$ The adapted version of the Personal Well-being Index-School Children (PWI-SC; Cummins \& Lau, 2005) was used to indicate the subjective well-being of children. The instrument was measured using an 11-point scale, 0 meaning Completely dissatisfied and 10 Completely satisfied. The instrument begins each question by asking "Right now, how satisfied are you..." and concludes with the following endings: "about the things you have?", "with your health?", "with the things you want to be good at?", "about getting on with the people you know?", "about how safe you feel?", "about doing things away from your home", and "about what may happen to you later in life?" The exact questions used in our study were not a literal Catalan translation of the questions posed by the aforementioned authors; a pilot study demonstrated that students who participated in the study struggled with the cognitive difficulty of the exact translations of these questions, and consequently the questions were reformulated for the purpose of this questionnaire. 
- A single item scale on overall life satisfaction (OLS). The item was measured using an 11-point scale, 0 meaning Completely dissatisfied and 10 Completely satisfied.

- Five items assessed satisfaction with additional specific life domains. The questionnaire asked: "Right now, how satisfied are you ..." "with your friends?", "with your family?", "with the sports you play?", "about your body?", and "with food?" These items were measured using an 11-point scale, 0 meaning Completely dissatisfied and 10 Completely satisfied.

The pilot study was conducted on a group of children displaying similar characteristics to the final sample (i.e. with regard to age, gender, school year, and school location) in order to test the degree of comprehension of the draft questionnaire. Consequently, the language in the tool was changed; the most important of these modifications entailed substituting the word feliç (happy) for the word content (content) in light of the fact that the latter word was more comprehensible than the former for children in this particular sociocultural context.

\section{Procedure}

After drafting the final version of the data collection tool, the directors of participating schools were contacted in order to explain the goals and progress of the study, underscore the importance of their collaboration, and request their consent.

The questionnaire was self-administered by students in their normal classroom during the school day. During each administration of the questionnaire, a researcher and one of the student's teachers were always on hand in order to explain the study and answer any potential questions which might arise. 


\section{RESULTS \\ Interest in food and eating-related decision-making}

The mean response to the question about student interest in food was $7.88(\mathrm{SD}=2.43)$ on a scale of 0 to 10 .

$51.1 \%$ of participants indicated that food is very interesting to them (they responded with either a 9 or a 10), while $31.1 \%$ expressed solid interest (responses between 6 and 8 ) and $17.8 \%$ said the topic was of little interest to them (responses $\leq 5$ ). There were no significant differences between these three groups in terms of gender.

The degree of importance children gave to different indicators which may influence eating are shown in Figure 1.

Insert Figure 1 about here

The main motivation when it comes to eating is the taste of food ("it tastes good"), followed by "it is good for my health." The indicators which received the lowest scores were those most closely connected to external influences ("someone recommended this food to me," "my friends also eat this food," and "I have seen the food on TV"). Girls scored "feeling good after eating" higher than boys $(\mathrm{t}(348.67)=2.70, \mathrm{p}=.007$ (two-tailed)), while boys gave greater importance to things they saw in advertisements $(t(367)=-2.168, p=.031$ (two-tailed)).

The major indicators described in Table 1 were analyzed by means of a Principal Component Analysis (PCA) using Varimax rotation, yielding 3 components explaining $55.80 \%$ of all variance. These components were as follows (see Table 1):

- Component 1 could be labeled "social influence" and explained $23.55 \%$ of the total variance. It included the following items: "I have seen this food on TV," "my friends also eat this food," "someone recommended this food to me," "this food is well-known," and "I have enough time to eat this food." 
- Component 2 was mainly related to health and explained $21.60 \%$ of the total variance. It included the following items: "my body needs this food," "my parents want me to eat this food," "this food is good for my health," and "this food makes me feel comfortable."

- Component 3, which we have labeled "hedonic," was composed of one item related to the taste associated with foods ("this food tastes good"). This component explained $10.66 \%$ of total variance.

Insert Table 1 about here

The indicator corresponding to "this food is easy to eat" was removed from the analysis as it loaded equally in two of the three aforementioned components. No statistically significant differences were observed in any of the three components with regard to gender.

Interest in food correlates positively and significantly with two of the three components: the health component - for both boys $(\rho=.24, p=.001)$ and girls $(\rho=.28, p<.0001)-$ and the hedonic component, for girls only $(\rho=.26, p=.001)$.

The subjective well-being of children

The responses study participants gave to items on the PWI-SC are shown in descending order in Table 2.

Insert Table 2 about here

As Table 2 shows, the items of satisfaction which received the highest mean score were "getting on with the people you know" and satisfaction "with your health" (the mean was higher than 9 for both). The overall mean score on the PWI-SC on a scale of 0 to 100 was 86.54 (SD = 10.54).

In keeping with the recommendations of the tool's authors, the index was recalculated, excluding the 29 subjects who gave extreme responses to all questions (responses of 0 or 10), resulting in a mean score of $85.25(S D=10.17)$. As there were no statistically significant 
differences between the two means, this study continued to utilize the data from all respondents.

There were no statistically significant differences with regard to gender for the PWI-SC index, but there were for the indicator "satisfaction with what may happen to you later in life" $(\mathrm{t}(365)=$ 2.206, $p=.0 .028$ (two-tailed)), girls $(M=8.50 ; S D=2.01)$ being the ones with the higher mean score compared to boys $(\mathrm{M}=8.03 ; \mathrm{SD}=2.11)$.

The OLS score $(M=9.09, S D=1.54)$ and satisfaction scores for other complementary life domains are high (means range from 8.62 to 9.71). The highest mean corresponded to satisfaction "with your family," while the lowest corresponded to satisfaction "with food" (see Table 3). There were no statistically significant differences with regard to gender for OLS or any of the items described in Table 3.

Insert Table 3 about here

\section{Food and well-being}

The correlation between interest in food and the PWI-SC was significant yet moderate $(\rho=.38$, $p<.001$ ). Correlations were similar for both genders (girls: $\rho=.38, p<.0001$; boys: $\rho=.35, p<$ $.0001)$.

Correlations were lowest between interest in food and OLS and other indicators of satisfaction which are not included on the PWI-SC, presented in Table 4.

Insert Table 4 about here

The highest correlation for boys was with satisfaction "with your body" $(\rho=.22, p=.001)$, while the highest correlation for girls was for satisfaction "with the sports you play" $(\rho=.30, p<$ .0001). The lowest correlations were satisfaction "with your family" for boys $(\rho=.15, p=.03)$ and satisfaction "with your friends" for girls $(\rho=.17, p=0.28)$.

The three principal components encapsulating the degree of importance which participants attributed to different components when it comes to eating (health, hedonism, and social 
influence) reflected statistically significant correlations with the PWI-SC, although these correlations are not particularly strong (health component: $\rho=.34, p<.0001$; hedonic component: $\rho=.27, p<.0001$; social influence component: $\rho=.19, p<.0001$ ).

Correlations between the PWI-SC and the 3 aforementioned components varied according to gender: for girls, the PWI-SC only showed a statistically significant positive correlation for the health component $(\rho=.26, p=.001)$ and the hedonic component $(\rho=.25, p=.002)$, while statistically significant positive correlations were found for all three components in boys (health: $\rho=.38, p<.001$; hedonic: $\rho=.29, p<.0001$; social influence: $\rho=.28, p=.002$ ).

The strongest correlation between the 3 components (health, hedonism, and social influence) and OLS were found in the importance given to questions of health. Only satisfaction "with your body" correlates with the three components (see Table 5).

Insert Table 5 about here

OLS correlates positively although modestly with the health component (girls: $\rho=.21, p=0$ .008 , boys: $\rho=.27, p<.0001$ ) and with the hedonic component, though in this case only for girls $(\rho=.21, p=.008)$.

The highest correlation for both boys and girls was found between the health component and the indicator entitled satisfaction "with your body" $(\rho=.24, p=.002$ and $\rho=.24, p=.001$, respectively).There were statistically significant correlations between the hedonic component and satisfaction "with your friends" $(\rho=.22, p=.006)$, and "with your family" $(\rho=.16, p=.048)$, again only for girls.

After conducting the analyses described above, a series of regression models were run in order to gain additional insight into the relationships between indicators related to food and personal well-being, using "satisfaction with food" (SATFOOD) as the link between these two constructs.

An analysis of SATFOOD results in terms of the three principal components classifying eatingrelated motivations and interest in food revealed that the model was significant (Adjusted $R^{2}=$ 
$.25, \mathrm{~F}(4.331)=29.25, \mathrm{p}<.0001)$. As Table 6 shows, the health component and interest in food appear as significant indicators when it comes to predicting SATFOOD.

Insert Table 6 about here.

The variable testing interest in food to explain SATFOOD accounts for $12 \%$ of variance. By taking as predictive variables the 11 items of importance when it comes to eating (rather than considering them in the 3-component grouping) to explain SATFOOD, we see that only 3 indicators (good for my health, parents want me to eat this, and have enough time to eat) contribute to explaining the SATFOOD results, corresponding to only of the two aforementioned components: health and social influence (Adjusted $R^{2}=.26$. F (3.339) $=41.05 p<.0001$ ).

Running this model with responses from only boys and then only girls revealed that for girls (Adjusted $\left.\mathrm{R}^{2}=.31 . \mathrm{F}(2.157)=36.37, \mathrm{p}<.0001\right)$ the variable which best explained the SATFOOD scores was the health component, followed by the hedonic component, whereas for boys (Adjusted $\left.R^{2}=.23 . F(2.181)=27.92, p=.008\right)$ the variable reflecting the highest beta value was interest in food, followed by the health component.

In order to explore which subjective well-being indicators act as predictors for SATFOOD we ran additional regression models with the PWI-SC and OLS separately.

Both models are significant (OLS: Adjusted $R^{2}=.21 . \mathrm{F}(1.356)=93.9, \mathrm{p}<.0001$ (Table 7); PWISC: Adjusted $\left.R^{2}=.22 . F(1.360)=102.33, p<.0001\right)$. Only 4 domains of the PWI-SC explain SATFOOD (see Table 8).

Insert Table 7 about here.

Insert Table 8 about here.

The results show that the only two domains with a statistically significant beta value are "health" and "the things you want to be good at" in the girls model (Adjusted $R^{2}=.12$. $F(2.341)=23.97$, $\mathrm{p}<.0001)$, whereas the model for boys included "health", "what may happen to you later in life", 
"getting on with the people you know" and "doing things away from your home", in decreasing order (Adjusted $\left.\mathrm{R}^{2}=.03 . \mathrm{F}(1.183)=7.11, \mathrm{p}=.008\right)$.

The degree to which complementary indicators of life satisfaction contribute to predicting SATFOOD values was explored through a linear regression model. The model revealed that all of the aforementioned indicators made a significant contribution, with the exception of satisfaction "with the sports you play" (Adjusted $\mathrm{R}^{2}=.21 \mathrm{~F}(3.361=32.45, \mathrm{p}<.0001)$ (see Table 9).

Insert Table 9 about here.

The beta values suggest that the indicator to best explain SATFOOD in the model described in Table 9 is satisfaction "with your body", while the variable to least explain it is "your friends". Subsequently, the same model was run separately for both boys and girls. The most important explanatory indicator for girls (Adjusted $R^{2}=.18 . F(1.168)=39.25, p<.0001$ ) was satisfaction "with the sports you play," "with your friends," and "with your family". By contrast, results for boys (Adjusted $\left.R^{2}=.25 . F(1.192)=31.12, p<.0001\right)$ showed that the indicator with the highest beta value was satisfaction "with your body," followed by satisfaction "with your family" and "the sports you play".

Finally, in order to analyze which indicators are significant in the above partial models when grouped together, we calculated a last linear regression model to explain SATFOOD. It is observed that this model includes 4 indicators, OLS being the indicator with the highest contribution $\left(\mathrm{R}^{2}\right.$ corregida $\left.=.40 . \mathrm{F}(4,328)=55.62, \mathrm{p}<.0001\right)($ Table 10$)$. Insert Table 10 about here.

The indicators with the highest explanatory capacity for SATFOOD using this model, after OLS, are the health component and "satisfaction with health" from the PWI-SC, for both genders, "satisfaction with your body" $\left(\mathrm{R}^{2}\right.$ corregida $\left.=.40 . \mathrm{F}(3.153)=34.59, \mathrm{p}<.0001\right)$ in the model for girls only and OLS and satisfaction with family $\left(R^{2}\right.$ corregida $\left.=.45 . F(4.174)=36.02, p<.0001\right)$ in the model for boys only (Table 11). 
DISCUSSION

The children who took part in this study displayed a high level of interest in food-related issues. Although there are no data to demonstrate it categorically, we believe that this keen interest could be attributed to the effectiveness of the various strategies implemented in Spanish schools to raise awareness about and promote healthy lifestyles among the child population (namely the Strategy for Nutrition, Physical Activity and the Prevention of Obesity, Spanish Agency for Food Safety and Nutrition 2005), and the Integral Plan for Health Promotion through Physical Activity and Healthy Eating (Government of Catalonia's Department of Health 2005).

Motivations for the sample children's food choices coincide with the results obtained by De Moura (2007), with sensory factors such as taste being the most prevalent factor, closely followed by health-related aspects. An analysis of the predominant reasons for children's evaluation of food reveals some differences between the genders. Girls prioritize feeling good after eating, unlike boys, who attach more importance than girls to eating things that they have seen in television advertisements. To understand the source of these differences, it might be useful to apply qualitative methodology techniques such as in-depth personal interviews and discussion groups.

The importance of health as an indicator influencing food choices, widely recognized among the adult population (Neumark-Sztainer et al. 1999), is also apparent in our results, demonstrating the extent to which the children surveyed are conscious of the link between food and health. This finding supports the claims of authors such as Contento (2007), who argues that it is during preadolescence that children start to become aware of the consequences of their actions in relation to what they eat.

As far as motivations for eating are concerned, the lowest means correspond to variables related to an external influence factor such as, for example, foods having been seen in advertisements. This contrasts with previous studies that suggest that children are particularly 
vulnerable to the influence of advertisements with respect to their eating habits (Mehta et al. 2010; Medeiros et al. 2008).

In line with the results obtained by De Moura (2007), the children in our sample who are most interested in food are those whose eating preferences are most influenced by health-related issues. The fact that girls of this age display a positive correlation between interest in food and a component of hedonic motivation for eating while boys do not is a phenomenon which would be worth studying in the future. The correlation between the factor of external influences and interest in food is weak and statistically insignificant.

The subjective well-being of children under 12 is an issue which has hardly been addressed in the literature owing to the difficulty involved in using concepts that are somewhat abstract in nature. We studied this notion by using an adapted version of the Personal Well-being Index (Cummins \& Lau 2005) to facilitate comprehension among the sample group of Catalan children.

The mean PWI-SC index scores for the children surveyed show that they have high levels of well-being, corroborating the positive opinions about their lives as a whole expressed by many children and teenagers in other research (Tomyn \& and Cummins 2011). The results obtained in our study are slightly higher and contain less variability of responses than the normative values defined by the authors for the Australian population ( $M=75, S D=12.65$; Cummins \& Lau 2005). This difference could be due to factors such as the size of the sample. It could also be attributed to the different sociocultural context involved. To verify this hypothesis, this study would have to be extended to include larger samples. Another hypothesis worth exploring in greater detail in the future, and one which we would particularly like to emphasize, is that normative values for the Australian population may be higher for the child population than for the adolescent and adult population.

In a previous study (González et al. in press) based on a sample of adolescent and young adults (15-24 years old) regarding their personal well-being (using the adult version of the Personal Well-being Index by Cummins and Lau (2006)), differences were found according to 
the gender of the participants. Contrarily, in our study there are no significant differences between boys and girls for the whole PWI-SC, but there is in relation to one specific domain "satisfaction with what may happen to you in later life", with girls scoring higher. This same result was found in the study by Tomyn \& Cummins (2011) using the same index (PWI-SC), but applied to 351 students aged 12 to 20 .

The life satisfaction domain to obtain the highest mean from the PWI-SC was "having good relationships with other people", which the children displayed a high awareness of, demonstrating the importance of interpersonal relationships and presumably the social support children receive from parents, classmates, teachers and close friends (Demaray \& Malecki 2002; Casas, 2010; Goswami, H, 2011).

The next most important domain (according to the mean scores obtained) is health, indicating that this is a prominent life concern among the child population. One of the domains to produce a low mean was security for future. A similar trend was observed with samples of teenagers and young people aged 15 to 24 (González et al. in press), and this result could be attributed to a heightened sense of uncertainty when thinking about the future. In light of this consideration, subsequent questionnaires might designate a specific period in the future (3 years, for example) to make it easier for participants from these age groups to respond.

As for OLS and satisfaction with other specific life domains studied in parallel to the PWI-SC, the importance of interpersonal relationships is again borne out by the respondents' answers concerning "satisfaction with family" and "satisfaction with friends", with these domains obtaining the highest scores. Both boys and girls scored high on OLS, and they were "satisfied with their body" as well as "with food", although the mean score for these specific aspects is slightly lower than the figures for "satisfaction with family" and "satisfaction with friends".

There are correlations, albeit moderate ones, between interest in food and the PWI-SC and the three components and the PWI-SC for both boys and girls. This might be due to the fact that none of the PWI-SC indicators explicitly refer to something as specific as food, their being constructed on a higher level of abstraction. 
Correlations between this interest in food and OLS and complementary domains of satisfaction explored alongside the PWI-SC are statistically significant yet weak, with the closest correspondence coming between interest and OLS. Boys and girls exhibit a different pattern of responses, to the extent that the strongest correlation in the case of girls relates to interest and "satisfaction with the sports you play", while for boys it is interest and "satisfaction with your body", suggesting different roots for their respective interest in food.

In this paper, SATFOOD has been understood as an indicator that allows us to evaluate those aspects that can help children enjoy their food and bring them to consider it as a pleasurable and important element for their well-being and quality of life. It is worth mentioning that the indicators that explain SATFOOD are not the same for boys and girls. Further studies are needed in order to analyze the reasons for such differences in more depth.

From the regression models we have run, we see that SATFOOD is explained through both food indicators and well-being indicators. These findings justify the consideration of SATFOOD as an indicator for evaluating elements related to food (health motivations) and others related to well-being (satisfaction with health, from the PWI-SC, OLS and satisfaction with your body) for the children participating in this study.

The results obtained suggest that adults are probably underestimating the role played by food in the lives of children aged between 10 and 12, with this issue having long been considered solely of interest to adults or, at most, to older children. It is important to understand how eating practices are conditioned from a young age and what affects this in order to be able to devise tools that help promote a more suitable dietary education for different groups, one that would bear in mind similarities and differences between each age bracket. There is a need to explore the role of indicators such as satisfaction with food, young people's interest in food, and the child population's levels of subjective well-being in order to open up new avenues of research in the field of health education and promotion. To achieve this goal, future research must be carried out in which a prominent role is afforded to children's perspectives, which will allow us to be able to look in greater depth at the connections between this population group's subjective well-being and satisfaction with food. 
Children's well-being includes the evaluations and aspirations of children themselves, while considering them active social actors who can reliably explain the experiences and meanings constituting their well-being.

It is important to point out some of the limitations of the study presented in this article. The sample used comprised schools that expressed an interest in taking part in the study. There is no way of knowing whether the sample is somehow skewed with respect to the rest of the schools in the region of Osona. It is possible that the schools not involved might exhibit distinctive characteristics in relation to the variables explored in this article. Ideally, future studies would collect data from a larger pool of schools.

The cross-sectional approach adopted in this study limits our ability to comprehend how the variables studied change over time. In other words, whether the children who are satisfied at present cease to be so over time or whether their well-being varies as a result of changes in the importance of food in their lives. It would be necessary to carry out a longitudinal study to examine this evolution.

Finally, it is worth contemplating the possible value of applying qualitative methodologies (such as discussion groups) in future studies in order to be able to investigate the different aspects discussed in this article in greater depth, as well as considering further work on the promotion of healthy eating habits based on the levels of interest in food shown in this study. This could serve as a starting point to improve children's motivation and participation with respect to both developing healthy practices initially promoted at a young age and maintaining them throughout adolescence, thereby fostering good eating habits.

\section{ACKNOWLEDGMENTS}

Support for the collection of data used in this article was provided by the Health Protection Agency of Osona, the Government of Catalonia's Department of Health, and the University of Vic. Comments by Enrico Bignetti have contributed enormously to improving the paper. 


\section{REFERENCES}

Aranceta, J. (1995). Nutrición en la edad evolutiva. In Serra, LI., Aranceta, J., \& Mataix, J., Nutrición y Salud Pública. Métodos, bases científicas y aplicaciones (2nd ed., 185-192). Barcelona, Spain: Masson.

Aranceta, J., Pérez, C., Serra, LI., \& Delgado, A. (2004). Hábitos alimentarios de los alumnos usuarios de comedores escolares en España. Estudio "Dime Cómo Comes". Atención Primaria, 33(3),131-139.

Casas, F. (2010). Subjective social indicators and child and adolescent well-being. Children Indicators

Research. DOI 10.1007/s1287-010-9093-z.

Contento, I. (2007). Nutrition education, linking research, theory and practice. EUA: Jones and Bartlett Publishers.

Contento, I., Koch, P., Lee, H., Sauberli, W., \& Calabrese, A. (2007). Enhancing personal agency and competence in eating and moving: Formative evaluation of a middle school curriculum. Choice, control and change. Journal of Nutrition Education Behaviour, 39(S5), 179S-186S.

Cummins, R. A. (2003). Normative life satisfaction: Measurement issues and a homeostatic model. Social Indicators Research, 64, 225-256.

Cummins, R. A. (1998). The second approximation to an international standard of life satisfaction. Social Indicators Research, 43, 307-334.

Cummins, R. A., Eckersley, R., Van Pallant, J., Vugt, J., \& Misajon, R. (2003). Developing a national index of subjective well-being: The Australian Unity Well-being Index. Social Indicators Research, 64, 159-190.

Cummins, R A., \& Lau, A. (2006). Manual: personal well-being index - adult. Fourth edition. Resource document. Melbourne: Australian Centre on Quality of Life, Deakin University. http://www.deakin.edu.au/research/acqol/instruments/well-being-index/pwiadult-english.pdf. Accessed 29 August 2011.

Cummins, R A., \& Lau, A. (2005). Manual: personal well-being index - school children. 
Third edition. Resource document. Melbourne: Australian Centre on Quality of Life, Deakin University. http://www.deakin.edu.au/research/acqol/auwbi/indextranslations/wbi-school-english.pdf. Accessed 29 August 2011.

Cummins, R A., \& Lau, A. (2004). Manual: personal well-being index - pre -school children. Second edition. Resource document. Melbourne: Australian Centre on Quality of Life, Deakin University. http://www.deakin.edu.au/research/acqol/instruments/wellbeing-index/. Accessed 29 August 2011.

Demaray, M., \& Malecki, C. (2002). The relationship between perceived social support and maladjustment for students at risk. Psychology in the Schools, 39(3), 305-316.

De Moura, S. L. (2007). Determinants of food rejection amongst school children. Appetite, 49, 716-719.

Eid., \& Diener, E. (2004). Global judgments of subjective well-being: Situational variability and long-terms stability. Social Indicators Research, 65, 245-277.

González, M., Casas, F., Malo, S., \& Viñas, F. (in press). Satisfaction with present safety and future security as components of personal well-being among young people: relationships with other psychosocial constructs. In Webb. D. \& Wills-Herrera, E. (ed.). Subjective Well-Being and Security. Social Indicators Research Series.

Goswami, H. (2011). Social relationships and children's subjective well-being. Social Indicators Research. DOI 10.1007/s11205-011-9864-z.

Government of Catalonia's Department of Health. (2005). Guia de l'alimentació saludable en l'edat

escolar. Resource document. Departament d'educació i Departament de salut de la Generalitat de Catalunya.

http://www10.gencat.cat/gencat/binaris/guia alimentacio escola tcm32-25805.pdf. Accessed 15 June 2011. Government of Catalonia's Department of Health. (2005). Pla integral per a la Promoció de la salut 
mitjançant l'Activitat física i l'Alimentació Saludable (PAAS). Resource document. Generalitat de Catalunya. http://www.gencat.cat/salut/depsalut/pdf/paas.pdf . Accessed 15 June 2011.

Mavrommatis, Y., Moynihan, P. J., Gosney, M. A., \& Methven, L. (2011). Hospital catering systems and their impact on the sensorial profile of foods provided to older patients in the UK. Appetite, 57, 14-20.

Medeiros, G., Amboni, R., \& Teixeira, E. (2008). Television use and food choices of children: Qualitative approach. Appetite, 50, 12-18.

Mehta, K., Coveney, J., Ward, P., Magarey, A., Spurrier, N., \& Udell, T. (2010). Australian children's views about food advertising on television. Appetite, 55, 44-55.

Neumark, D., Story, M., Perry, C., \& Cassey, M. (1999). Factors influencing food choices of adolescents: Findings from focus-group discussions with adolescents. Journal of The American Dietetic Association, 99(8), 929-937.

Serra, LL., Ribas, L., García, R., Pérez, C., Peña, C., \& Aranceta, J. (2002). Hábitos alimentarios y consumo de alimentos en la población infantil y juvenil española (19982000): variables socioeconómicas y geográficas. In Serra, LI., \& Aranceta, J. Alimentación infantil y juvenil: Estudio EnKid (3, 13-19). Barcelona, Spain: Editorial Masson.

Spanish Agency for Food Safety and Nutrition. (2005). Estrategia para la nutrición, actividad física y prevención de la obesidad (NAOS). Resource document. Ministerio de Sanidad y Consumo de España. http://www.naos.aesan.msps.es. Accessed 25 June 2011.

Tomyn, A., \& Cummins, R. (2011). The subjective well-being of high-school students: Validating the personal well-being index-school children. Social Indicators Research, 3(101), 405-418.

Watters, C., Sorensen J., Fiala A., \& Wismer, W. (2003). Exploring patient satisfaction with foodservice through focus groups and meal rounds. Journal of the American Dietetic Association, 103, 1347-1349. 
Figure 1 Importance given to different indicators for food decision-making

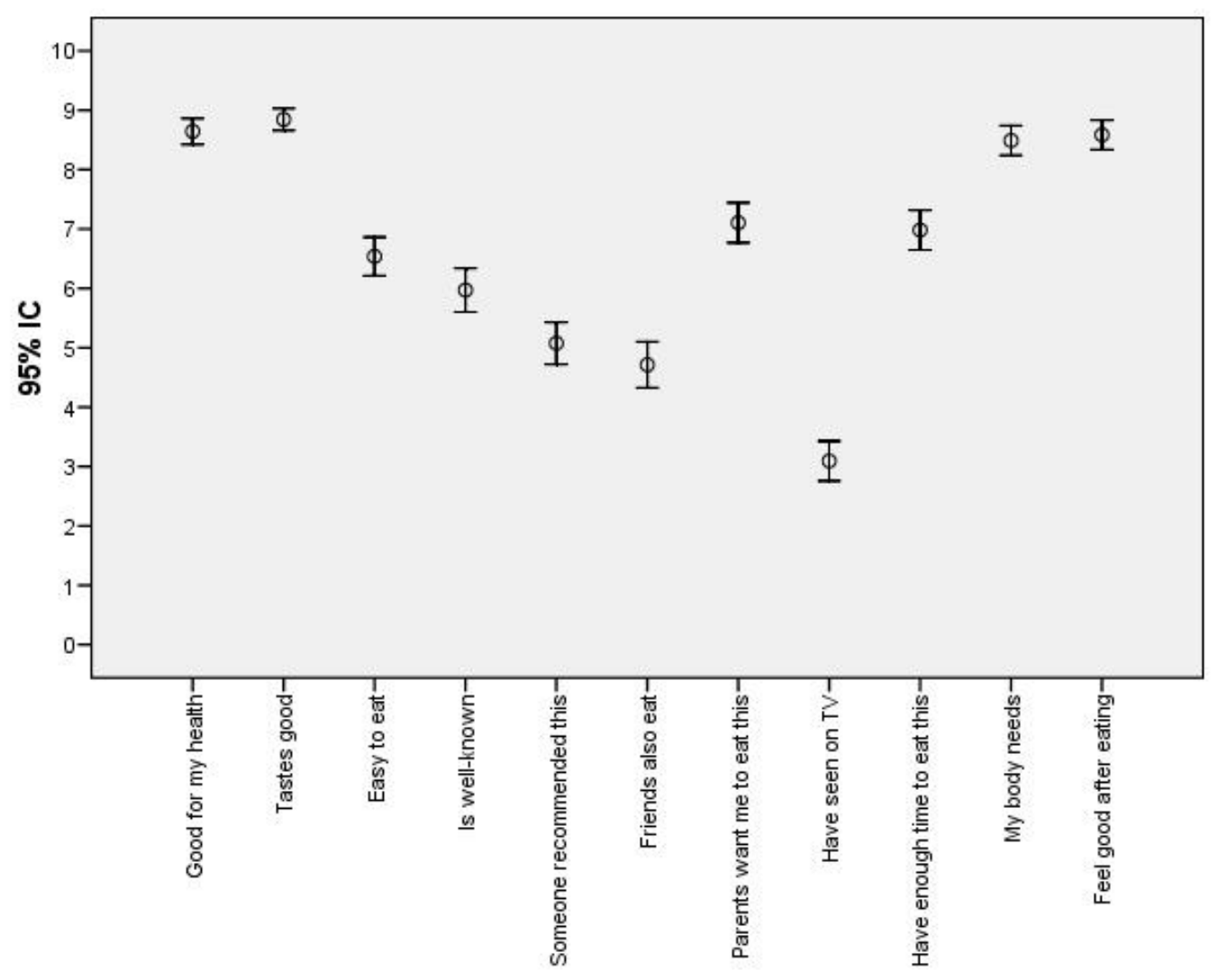


Table 1 Principal component analysis (PCA): Rotated component matrix of the different indicators related to food decision-making (loadings below .2 are not displayed)

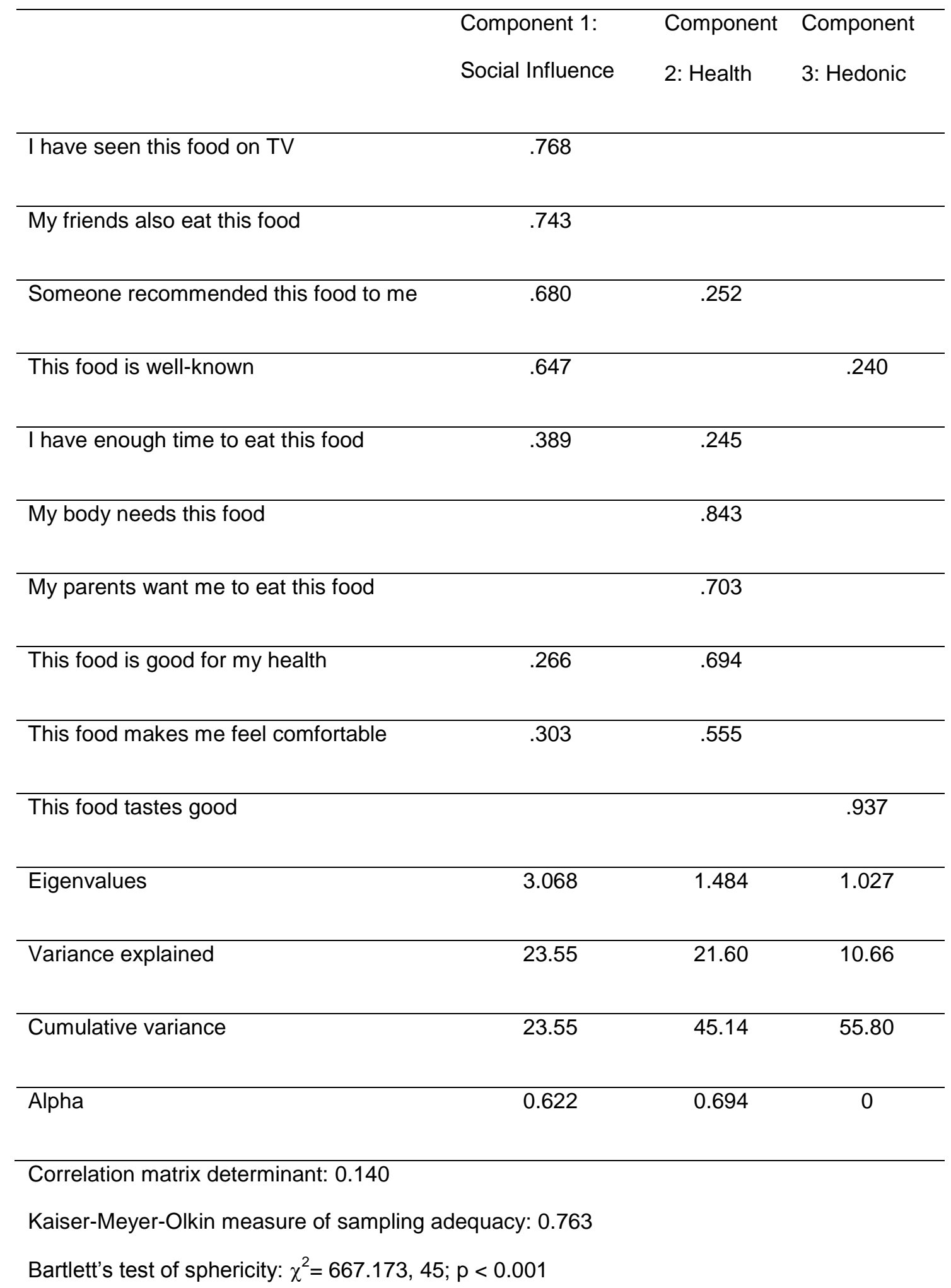


Table 2 Means and standard deviations of items from the PWI-SC

\begin{tabular}{lcc}
\hline Satisfaction... & Mean & SD \\
\hline With getting on with the people you know & 9.23 & 1.46 \\
& & \\
\hline With your health & 9.19 & 1.45 \\
& & \\
\hline With the things you have & 8.69 & 1.78 \\
& & \\
\hline With the things you want to be good at & 8.55 & 1.80 \\
& & \\
\hline With how safe you feel & 8.46 & 1.80 \\
& & \\
\hline With what may happen to you later in life & 8.25 & 2.07 \\
& & \\
\hline With doing things away from your home & 8.11 & 2.19 \\
& & \\
\hline
\end{tabular}

Table 3 Means and standard deviations for complementary satisfaction with life domains explored

\begin{tabular}{lcc}
\hline Satisfaction... & Mean & SD \\
& & \\
\hline With your family & 9.71 & 1.00 \\
& & \\
\hline With your friends & 9.26 & 1.59 \\
& & \\
\hline With the sports you play & 8.86 & 2.18 \\
& & \\
\hline With your body & 8.77 & 1.83 \\
& & \\
\hline With food & 8.62 & 2.94 \\
& & \\
\hline
\end{tabular}


Table 4 Spearman correlations between interest in food, satisfaction with the other life domains explored and OLS

\begin{tabular}{lc}
\hline Satisfaction... & Interest in food \\
\hline With your friends & $.13, p=.015$ \\
\hline With your family & $.14, p=.008$ \\
\hline With the sports you play & $.18, p=.001$ \\
\hline With your body & $.23^{*}$ \\
\hline OLS & $.28^{*}$ \\
\hline * Significant difference, $p<0.001$
\end{tabular}

Table 5 Spearman correlations between the three components identified in the PCA with OLS and other satisfaction with life domains

\begin{tabular}{|c|c|c|c|}
\hline Satisfaction... & $\begin{array}{l}\text { Health } \\
\text { Component }\end{array}$ & $\begin{array}{l}\text { Hedonic } \\
\text { Component }\end{array}$ & $\begin{array}{l}\text { Social influence } \\
\text { Component }\end{array}$ \\
\hline With your friends & $.16, p=.003$ & $.16, p=.003$ & - \\
\hline With your family & $.22^{*}$ & $.12, p=.039$ & - \\
\hline With the sports you play & $.23^{*}$ & $.11, p=.038$ & - \\
\hline With your body & $.24^{*}$ & $.14, p=.008$ & $.12, p=.025$ \\
\hline OLS & $.25^{*}$ & $.14, p=.010$ & - \\
\hline
\end{tabular}

${ }^{*}$ Significant difference, $p<0.001$ 
Table 6 Linear regression of the three components related to food decision-making and interest in food on Satisfaction with food

\begin{tabular}{llll}
\hline & $\boldsymbol{\beta}$ & $\mathbf{t}$ & Sig. \\
& & & \\
\hline Health & .37 & 7.70 & $\mathrm{p}<.0001$ \\
Component & & & \\
& & & \\
\hline Interest in food & .25 & 5.10 & $\mathrm{p}<.0001$ \\
& & & \\
\hline
\end{tabular}

Table 7 Linear regression of OLS on Satisfaction with food

\begin{tabular}{llll}
\hline & $\boldsymbol{\beta}$ & $\mathbf{t}$ & Sig. \\
& & & \\
\hline OLS & .47 & 10.12 & $\mathrm{p}<.0001$ \\
& & & \\
\hline
\end{tabular}

Table 8 Linear regression of PWI-SC domains and OLS on Satisfaction with food

\begin{tabular}{lllll}
\hline & $\boldsymbol{\beta}$ & $\mathbf{t}$ & Sig. \\
\hline OLS & & & \\
& & & \\
& & & \\
\hline With the things you want to be good at & .38 & 2.74 & $\mathrm{p}=.006$ \\
& & & & \\
\hline Satisfaction with health & .31 & 6.20 & $\mathrm{p}<.0001$ \\
& & & & \\
\hline With doing things away from your home & .15 & 3.05 & $\mathrm{p}=.002$ \\
& & & \\
\hline With what may happen to you later in life & .12 & 2.42 & $\mathrm{p}=.016$ \\
& & & \\
\hline
\end{tabular}


Table 9 Linear regression of other satisfaction with life domains on Satisfaction with food

\begin{tabular}{llll}
\hline Satisfaction with... & $\boldsymbol{\beta}$ & $\mathbf{t}$ & Sig. \\
\hline With your body & .36 & 7.44 & $\mathrm{p}<.0001$ \\
& & & \\
\hline With your family & .17 & 3.44 & $\mathrm{p}=.001$ \\
& & & \\
\hline With your friends & .11 & 2.20 & $\mathrm{p}=.028$ \\
\hline
\end{tabular}

Table 10 Final linear regression of previous statistically significant indicators on Satisfaction with food

\begin{tabular}{llll}
\hline & $\boldsymbol{\beta}$ & $\mathbf{t}$ & $\mathbf{S i g}$. \\
\hline OLS & .325 & 6.50 & $\mathrm{p}<.0001$ \\
\hline Health Component & & & $\mathrm{p}<.0001$ \\
\hline Satisfaction with your health (PWI-SC) & .175 & 3.62 & $\mathrm{p}<.0001$ \\
& & & \\
\hline Satisfaction with your body & .105 & 2.06 & $\mathrm{p}=.040$ \\
\hline
\end{tabular}


Table 11 Final linear regression of previous statistically significant indicators on Satisfaction with food by gender

\begin{tabular}{ll}
\hline Girls & Boys
\end{tabular}

\begin{tabular}{|c|c|c|c|c|c|c|c|}
\hline & $\beta$ & $\mathbf{t}$ & Sig. & & $\beta$ & $\mathbf{t}$ & Sig. \\
\hline Health Component & 0.40 & 5.96 & $\begin{array}{l}p< \\
.0001\end{array}$ & OLS & 0.47 & 7.73 & $\begin{array}{l}\mathrm{p}< \\
.0001\end{array}$ \\
\hline $\begin{array}{l}\text { Satisfaction with your } \\
\text { health (PWI-SC) }\end{array}$ & 0.24 & 3.47 & $p=.001$ & Health Component & 0.22 & 3.56 & $\begin{array}{l}\mathrm{p}< \\
.0001\end{array}$ \\
\hline Satisfaction with your body & 0.23 & 3.36 & $p=.001$ & $\begin{array}{l}\text { Satisfaction with your } \\
\text { health (PWI-SC) }\end{array}$ & 0.130 & 2.11 & $p=.031$ \\
\hline & & & & $\begin{array}{l}\text { Satisfaction with your } \\
\text { family }\end{array}$ & 0.132 & 2.18 & $p=.036$ \\
\hline
\end{tabular}


The paper is carefully written and the importance of the field is highlighted. However, there are some suggestions that could improve the writing of the paper so that readers can get the best of it.

1. The use of the term "indicator" must be reviewed, in some parts of the text the relation of the predictor $\mathrm{x}$ indicator is not clear (ex. "The results obtained suggest that satisfaction with food is a relevant indicator in the exploration of children's subjective well-being?" in the abstract suggesting that satisfaction with food is the indicator of subjective well-being, but it is the opposite. The use of the term indicator has been reviewed and substituted by predictor or variable when necessary.

2. There is a key word "subjective children". Is this correct? Thanks for saying; the correct key word is children without the word subjective.

3. In page 2, the last phrase of the last paragraph is not clear ("However, these largely focus on an assessment of the service received and the nutritional quality of?"). The verb has been changed to increase comprehension.

4. In the sample, page 5, the last paragraph initiate with numbers, what is not recommended to be used. The sentence has been rephrased, now it begins with "In terms of gender..."

5. The OLS mentioned in the instruments could have the reference of Campbell, A., Converse, P.E., \& Rogers, W.L. (1976). The quality of American life: Perceptions, evaluations, and satisfactions. New York: Russell Sage. Done

6. In the procedure, the author(s) inform that they requested the consent of school's directors, but $t$ ! here is no information about parents and children consent. Additional information on this issue has been added in the text.

7. In results, the differences are presented using the $t$ test. I suggest presenting also the effect size of the differences, because they can be significant but with very low effect size. The eta value has been added in order to offer information about the effect size of the differences.

8. The PCA does not seem to be necessary. The results do not appear to contribute to the objectives of the paper. The items can be directly regressed with satisfaction with food. The PCA has been preserved because we consider interesting the three components coming from this analysis as they can be connected with the scientific literature. However, in order to avoid confusion, it has been deleted in the results section any regression model calculated directly with the items.

9. Linear Regression is used, but the author(s) don't mention the method used (enter, stepwise?). The stepwise method has been the one used. Now it is explained in the text. In addition, tables 6 to 11 should present the Confidence Interval, according to APA style. The confidence interval for those tables has been added. 
10. Results showed in table 7 are repeated in table 8 . I suggest removing table 7. According to the reviewers' comments, the results displayed in table 8 have been modified so now results presented in table 7 are different from table 8.

11. In page 13 , the corrected R is written as R2 corregida three times. It must be corrected. It has been corrected. Thanks for saying.

12. In page 16, the last phrase is not clear ("This might be due to the fact that none of the PWI$\mathrm{SC}$ indicators explicitly refer to something as specific as food, their?"). The sentence has been rephrased.

I hope the author(s) finds the comments helpful in a further revision of their paper. 
Reviewer \#2: This article describes an interesting study focusing on what appears to be an under-researched aspect of children's life satisfaction. It has the potential to make an important contribution to the research literature and to stimulate further research on the role which food plays in children's lives and the links between this topic and life satisfaction. Overall, I felt that the material described in the paper is definitely worthy of publication. However I feel that there is a need to do further work on the conceptual approach to exploring connections between the variables of interest and on the approach to statistical analysis, and for these aspects of the study to be more fully explained in the paper before presenting the results. I also thought that the structure of presentation of the results could be made clearer to enable th! e reader to follow the line of argument. An additional section on the structure of the analysis has been included before the results with the intention of clarifying all the analysis performed and the justification of the variables included.

I think the most important thing is to clarify the approach taken to the various levels of measurement of life satisfaction. As I understand it, there is a need to view life satisfaction as hierarchical with overall life satisfaction as the highest order. At the moment the article uses variables from different levels in the same analysis. For example the analysis in Table 8 uses overall life satisfaction and satisfaction with particular domains in a regression model to explain satisfaction with food. I think some theoretical justification is needed for this approach and for the direction of analysis here as it is more typical (as in Cummins' work using the PWI) to use domain satisfaction items as explanatory variables to predict overall life satisfaction.

According to this suggestion, OLS in table 8 has been removed from the analysis, so only the domains of the PWI-SC have been included. Because we wanted to explore predictors of satisfaction with food, this is the only independent variable considered in the paper.

Some other more detailed suggestions are as follows:

- In the abstract and on page 17, the paper suggests that there is a belief that food is not an importan! $t$ issue for children. Some evidence is needed to support this statement. As there is not much literature on that issue reinforcing that idea, we've decided to delete this statement in the abstract and to add additional information on page 17.

- On page 2 it would be helpful to to review any previous literature (relating to children or adults) on the links between food and life satisfaction. Two additional references have been added in the text. The literature is very scarce in relation to that issue, that's why we cannot extend on that point.

- Regarding page 3, Lines 1 to 15 , it did not seem to me that the article fully pursued the argument described here and this paragraph may need to be revised. A paragraph has been re-phased in order to make clearer what the paper focuses on.

- On page 5, Lines 19 to 21, it would be helpful here or in the Discussion section to explain any implications of the fact that all participating children were regular users of school food. Does 
this have any particular implications in terms of the socio-economic status of these children? Additional information in the method section has been added.

- In the section describing the measures used, pages 6 and 7, it would be important to provide some more explanation on the origin of, and reasons for, the use of the measures making up the second set of items (page 6, lines 19 to 29) and the last set of items (page 7, lines 6 to 13). Addtional information has been added in order to explain the correspondence between items and scales and the objectives.

- Page 14, Lines 7 to 19. This paragraph seemed hypothetical a! nd should be considered for deletion. The autors present the statement as an hypothesis worth considering. For that reason the paragraph has not been deleted but complemented with another sentence to make things clearer.

- There is some interesting material on gender differences in the analysis, this does create additional complexity given the amount of material and analysis presented in the paper. One option would be to exclude this material and publish it separately. On the other hand, if it is to remain in the paper, I think that there is a need to draw some clearer conclusions from this aspect of the analysis. We think it is important to preserve in this paper the exploration of gender differences. But as we understand the point raised, some extra explanation have been added both in the introduction and in the discussion.

All in all, there is some very interesting and useful material in the paper, but I feel there is a need for a clearer and more clearly explained framework for the analysis. 
FOOD INDICATORS AND THEIR RELATIONSHIP WITH 10 TO 12 YEAR-OLDS' SUBJECTIVE WELL-BEING

Cristina Vaquéa ${ }^{a}$ Mònica González ${ }^{b}$, Ferran Casas ${ }^{b}$

aUniversity of Vic (Spain). Faculty of Health Sciences and Well-being. C/ Sagrada Família, 7. 08500 Vic. (Barcelona-Spain). cristina.vaque@uvic.cat

${ }^{\mathrm{b}}$ University of Girona (Spain). Quality of Life Research Institute. M-20. Campus Montilivi. 17071 Girona. monica.gonzalez@udg.edu, ferran.casas@udg.edu 


\begin{abstract}
This study aims to test subjective indicators designed to analyze children's predisposition towards food consumption, to assess their subjective well-being, and to explore the relationship between subjective well-being, predisposition towards food consumption and satisfaction with food. Gender differences are analyzed. It was conducted on 371 children aged 10 to 12 by means of a self-administered questionnaire.
\end{abstract}

Results show that children's motivations in relation to taste and health are relevant subjective indicators of their predisposition towards food consumption. They demonstrate a high subjective well-being, measured using Cummins \& Lau's adapted version of the Personal Well-Being Index-School Children (PWI-SC) (2005), overall life satisfaction (OLS) and satisfaction with various life domains (friends, family, sports, food and body).

In order to analyze the relationship between the three aforementioned constructs, regression models were conducted. The interest children have in food, the importance they give to different reasons for eating, scores from the PWI-SC, OLS and satisfaction with various life domains were regressed on satisfaction with food. It was observed that OLS, health motivations, satisfaction with health from the PWI-SC and satisfaction with doing things away from home (also from the PWI-SC), contribute to explaining satisfaction with food.

The results obtained suggest that the different indicators for children's predisposition towards food consumption explored here and subjective well-being are relevant determinants of satisfaction with food. They also appear to reinforce the importance of exploring food satisfaction in any study aimed at analyzing the well-being of the 10 to 12 year-old population.

KEY WORDS: Personal well-being, children, subjective indicators, satisfaction with food. 
INTRODUCTION

The scientific community first began to take an interest in the relationship between food and health in the 1950s, a decade that saw the discovery of the link between certain eating habits and a decreased risk of arteriosclerosis. Besides being a nutritional process, eating has significant connotations relating to pleasure, and indeed serves as an element of social, cultural and religious identification all at once. It also promotes and intervenes in the establishment of interpersonal and emotional relationships that ultimately shape individuals' eating habits, thereby having a bearing on their long-term health (Departament de Salut de la Generalitat de Catalunya 2005a).

Food is also one of the key exogenous factors that affect children's proper growth and development (Aranceta et al. 2004). This highlights the importance of addressing the issue of food from an early age. Children grow and change quickly during their school years, with the period between the ages of 6 and 12 representing one of the most important for the development of their cognitive, physical and social skills. Although children begin to develop causal reasoning during this stage, the criteria that affect their choice of food remain rather immediate. That said, children at this age do start to take an interest in the links between food and health (Contento 2007). Furthermore, they display an increasing amount of independence, leading to the expansion of their relationships and a heightened capacity to make decisions (Aranceta 1995), some of which may revolve around aspects relating to food.

With regard to gender, although not considered a determinant variable like availability of food, upbringing, taste, or friends' influence, some studies highlight that it does have some impact on food preferences. In this respect, girls seem to be more likely to select healthier foods than boys in order to control weight, whereas boys' greater energy requirements and desire to become stronger could provide some explanation for their preference for more energy-dense food groups (Pich et al 2010; Neumark-sztainer et al 1999; Cooke \& Wardle 2005). Further research is needed, however, in order to take a more in-depth look at boys' and girls' motivations when it comes to eating. 
Research conducted on child nutrition in recent years (Serra et al. 2002; Contento et al. 2007, among others) has demonstrated a need to deal with this issue, in part due to the dietary imbalance and health issues in evidence among the child population. Studies have also been carried out to analyze eating habits and satisfaction in relation to food received in specific contexts (in schools, hospitals, etc.). However, these largely focused on evaluating the service received and the nutritional quality of the menus served (Watters et al. 2003; Mavrommatis et al. 2011) and fail to take into account the possible role of food in children's subjective well-being and how it relates to their opinions, perceptions and evaluations.

Two exceptions to the above are the study by Proctor, Linely \& Maltby (2009), which reports lower levels of life satisfaction in children with obesity and food disorders, and the study by Valois, Zulling, Huebner \& Wanzer (2003), who found that lower levels of subjective well-being in children are associated with poorer diet habits.

This article argues that in order to understand individuals' eating habits and their predisposition towards food consumption one must go beyond strictly dietary and nutritional indicators for different foods and consider a range of possible psychosocial indicators. These indicators concern the immediate context in which food is consumed (eating habits in the family home and environmental aspects of food, relationships with dining companions), a wider social context (the importance given to food, beliefs about particular foods, the application of regulations on dietary matters) and a more individual dimension: each person's judgments with respect to different aspects of life, including subjective well-being and personal food preferences.

This study will focus on the last of the aforementioned areas (the more individual dimension), leaving the exploration of other aspects for future research. A key concept we aim to analyze in this research is children's satisfaction with food as a potential component of children's subjective well-being. By satisfaction with food we are referring to the evaluation of those aspects that can help children enjoy their food and lead them to consider it a pleasurable and important element for their well-being and quality of life. 
Subjective well-being is generally held to be a multidimensional assessment reflecting the combination of a cognitive process (satisfaction with life both as a whole and in relation to various specific domains: health, school, family, friends and relationships with other people, among others) with two affective processes (presence of positive affect and absence of negative affect) (Argyle 1987; Diener 1984; Diener \& Larsen 1993; quoted in Eid \& Diener 2004). This study focuses on the more cognitive side of well-being, leaving an analysis of the more affective aspects for future research.

Major contributions to the study of subjective well-being have been made by Cummins (1998; 2003), who argues for the inclusion of various domains when it comes to analyzing the judgments that people make about their lives when questioned about their personal wellbeing. He also contends that measuring the variable of overall life satisfaction involves a homeostatic control mechanism; similar to the way in which blood pressure is measured, but psychological. This means that the range of variation in personal well-being scores recorded among people from the same country and between different countries tends to be limited, pointing to the existence of normative values for well-being.

Cummins et al. (2003) have developed a tool to investigate subjective well-being, which they called the Personal Well-being Index (PWI). It assesses responses regarding level of satisfaction in the following domains: standard of living, personal health, life achievement, personal relationships, personal safety, community-connectedness, future security, and spirituality and religion. It also includes satisfaction with life as a whole. Various versions of this index have been designed to meet the specific needs of different age groups: adults (PWI-A) (Cummins \& Lau 2006), school children (PWI-SC) (Cummins \& Lau 2005) and pre-school children (PWI-PS) (Cummins \& Lau 2004).

In relation to gender, the results of different studies carried out on Australian and Spanish adolescents and young adults (Tomyn \& Cummins 2011; Tomyn et al. 2011; González et al. 2012), some using an adaptation of the PWI-A and others the PWI-SC, are not conclusive. In one study, females' scores are higher than males', and in two others this trend is reversed. No 
studies have explored the personal well-being of children under 12 , however. This is therefore a pending issue that this paper will attempt to cover.

In light of the above, the aims of this study are: (1) to test subjective indicators designed to analyze the predisposition of children aged 10 to 12 towards food consumption, (2) to assess their subjective well-being, (3) to explore the relationship between these two phenomena and satisfaction with food, and (4) to explore the different patterns displayed by participants in relation to these phenomena according to gender.

\section{METHOD}

The data analyzed in this study were collected within the context of a larger research study on school food carried out in 2008 in the region of Osona (Catalonia, north-east Spain), which was funded by the Government of Catalonia's Department of Health and the University of Vic. Of the 79 schools in the region, 26 (32.9\%) expressed an interest in participating. The target population of this study was recruited from 18 of these schools. Eight schools were excluded because they did not include primary-age students; another school with a special education programme serving intellectually-impaired children was also excluded.

In light of the fact that the data analyzed in this article are extracted from a school dining-room study, it is clear that participating children are all regular users of school-provided food services. In Spain, these services are accessible to all families, they are organized by the Parents' Associations and using them does not reflect a particular socio-economic status.

\section{Sample}

Data are taken from a total of 371 children in the region of Osona in their last two years of primary school (students were between 10 and 12 years of age). This sample comprises $25.82 \%$ of all children enrolled in the last two years of primary school in the 18 participating 
schools. This age group was selected for two reasons: the difficulty of assessing the well-being of children under 10 , and the fact that other studies have reflected a growing interest in dietary issues for children in this cohort.

The majority of participating schools were state schools $(77.8 \%$, mirroring the total distribution of state schools in the region), while the remainder of participating entities were publicly-funded private schools from the region (22.2\%). Half of these schools (50\%) were located in semi-rural areas (with populations between 2,000 and 5,000 residents), while $33.3 \%$ were in urban areas (with more than 5,000 residents) and $16.6 \%$ of schools were in rural areas (with less than 2,000 residents).

In terms of gender, $53.6 \%$ of the students were male $(n=199)$ and $46.4 \%$ were female $(n=$ 172). The mean age of these students was 10.73 years old $(S D=0.65) .38 .5 \%$ of students were 10 years old ( $21 \%$ boys and $17.5 \%$ girls), $50.1 \%$ were 11 ( $26.7 \%$ boys and $23.5 \%$ girls), and the remaining $11.3 \%$ were $12(5.4 \%$ boys and $6 \%$ girls $)$.

\section{Instruments}

Data were collected using a questionnaire designed specifically for this study and containing the scales and items described below. In order to test objective 1, the following questions were included in the questionnaire:

I. One item regarding children's global interest in food scored on an 11-point scale, with 0 representing not interested at all and 10 representing extremely interested.

II. A group of items evaluating the importance attributed to various eating-related topics: "this food is good for my health," "this food tastes good," "this food is easy to eat," "this food is well-known," "someone recommended this food to me," "my friends also eat this food," "my parents want me to eat this", "I have seen the food on TV", "I have enough time to eat", "my body needs this food," and, finally, "I feel good after eating this food" (scored from $0=$ not at all to $10=$ very much).

Objective 2 has been developed through the application of: 
I. The adapted version of the Personal Well-being Index-School Children (PWI-SC; Cummins \& Lau, 2005) was used to indicate the subjective well-being of children. The instrument was measured using an 11-point scale, 0 meaning Completely dissatisfied and 10 Completely satisfied. The instrument begins each question by asking "Right now, how satisfied are you..." and concludes with the following endings: "about the things you have?", "with your health?", "with the things you want to be good at?", "about getting on with the people you know?", "about how safe you feel?", "about doing things away from your home", and "about what may happen to you later in life?" The exact questions used in our study were not a literal Catalan translation of the questions posed by the aforementioned authors; a pilot study demonstrated that students who participated in the study struggled with the cognitive difficulty of the exact translations of these questions, and consequently the questions were reformulated for the purpose of this questionnaire.

II. A single item scale on overall life satisfaction (OLS) (Campbell, Converse, \& Rogers, 1976).The item was measured using an 11-point scale, 0 meaning Completely dissatisfied and 10 Completely satisfied.

III. Four items assessed satisfaction with additional specific life domains. The questionnaire asked: "Right now, how satisfied are you ..." "with your friends?", "with your family?", "with the sports you play?", "about your body?"These items were measured using an 11-point scale, 0 meaning Completely dissatisfied and 10 Completely satisfied.

With the aim of testing objective 3 , an additional item on satisfaction with food was included in the questionnaire, using the same 11-point scale and the same question.

The pilot study was conducted on a group of children displaying similar characteristics to the final sample (i.e. with regard to age, gender, school year, and school location) in order to test the degree of comprehension of the draft questionnaire. Consequently, the language in the tool was changed; the most important of these modifications entailed substituting the word feliç (happy) for the word content (content) in light of the fact that the latter word was more comprehensible than the former for children in this particular sociocultural context. 


\section{Procedure}

After drafting the final version of the data collection tool, the directors of participating schools were contacted in order to explain the goals and progress of the study, underscore the importance of their collaboration, and request their consent. Regular ethical procedures for research involving children in Spain accept the passive consent of parents when Parents' Associations have been informed and the questionnaires are anonymous and do not include personally sensitive items, which is the case of the questionnaire used here. Children were asked for their co-operation after being informed of the aims of the research and the fact that they were free to stop answering the questionnaire at any time.

The questionnaire was self-administered by students in their normal classroom during the school hours. During each administration of the questionnaire, a researcher and one of the student's teachers were always on hand in order to explain the study and answer any potential questions which might arise.

\section{Structure of the analysis}

The results of this paper have been divided into three different sections. The first section on "interest in food and eating-related decision-making" responds to the first objective of testing indicators designed to analyze 10 to 12 year olds' predisposition towards food consumption. Some studies have been conducted to analyze reasons for children's preferences on different kinds of food. However, they do not consider children's interest in their exploration of foodrelated behaviors. We believe that interest might play an important role in decisions about food as it may be connected to different attitudes towards food consumption. This is why, contrary to other studies we have found in the literature, this variable has been included in the paper. Means and standard deviations of the item regarding children's global interest in food and a group of items evaluating the importance attributed to various eating-related topics are therefore calculated. A principal component analysis (PCA) of these last items was performed in order to extract different components which could be used for subsequent analysis. Gender differences 
are explored through the Student's T-test. Finally, Spearman correlations between interest in food and the components emerging from the PCA were also performed.

The second section, related to "the subjective well-being of children", deals with calculating the means and standard deviations of the adapted PWI-SC domains, the OLS and satisfaction with additional specific life domains, including satisfaction with food. This section responds to the second objective of assessing children's subjective well-being. Again, gender differences are explored through the Student's T-test.

The third section is related to the third objective (studying potential links between food and subjective well-being). With this in mind, Spearman correlations were calculated between foodrelated indicators and subjective well-being indicators. Finally, different regressions models were performed using the stepwise method taking satisfaction with food as the independent variable and food-related and subjective well-being indicators as predictors. Models for boys and girls were also calculated separately in order to respond to objective 4 (exploring the different patterns displayed by participants in relation to the explored phenomena according to gender). As explained in the introduction, satisfaction with food is generally understood in the literature as a variable that allows the quality of a food-providing service to be evaluated, but not as something that can be both related to children's predisposition towards food consumption and their subjective well-being. Results are expected to broaden researchers' perspectives on the explored issues and they cannot therefore be easily compared to other studies carried out to date.

RESULTS

Interest in food and eating-related decision-making

The mean response to the question about student interest in food was $7.88(S D=2.43)$ on a scale of 0 to 10 . 
$51.1 \%$ of participants indicated that food is very interesting to them (they responded with either a 9 or a 10), while 31.1\% expressed solid interest (responses between 6 and 8 ) and 17.8\% said the topic was of little interest to them (responses $\leq 5$ ). There were no significant differences between these three groups in terms of gender.

The degree of importance children gave to different indicators which may influence eating are shown in Figure 1.

\section{Insert Figure 1 about here}

The main motivation when it comes to eating is the taste of food ("it tastes good"), followed by "it is good for my health." The indicators which received the lowest scores were those most closely connected to external influences ("someone recommended this food to me," "my friends also eat this food," and "I have seen the food on TV"). Girls scored "feeling good after eating" higher than boys $(\mathrm{t}(348.67)=2.70, p=.007$ (two-tailed), $\eta=.136)$, while boys gave greater importance to things they saw in advertisements $(\mathrm{t}(367)=-2.17, \mathrm{p}=.031$ (two-tailed), $\eta=.112)$.

The major indicators described in Table 1 were analyzed by means of a Principal Component Analysis (PCA) using Varimax rotation, yielding 3 components explaining $55.80 \%$ of all variance. These components were as follows (see Table 1):

- Component 1 could be labeled "social influence" and explained $23.55 \%$ of the total variance. It included the following items: "I have seen this food on TV," "my friends also eat this food," "someone recommended this food to me," "this food is well-known," and "I have enough time to eat this food."

- Component 2 was mainly related to health and explained $21.60 \%$ of the total variance. It included the following items: "my body needs this food," "my parents want me to eat this food," "this food is good for my health," and "this food makes me feel comfortable."

- Component 3, which we have labeled "hedonic," was composed of one item related to the taste associated with foods ("this food tastes good"). This component explained $10.66 \%$ of total variance. 
The indicator corresponding to "this food is easy to eat" was removed from the analysis as it loaded equally in two of the three aforementioned components. No statistically significant differences were observed in any of the three components with regard to gender.

Interest in food correlates positively and significantly with two of the three components: the health component - for both boys $(\rho=.24, p=.001)$ and girls $(\rho=.28, p<.001)-$ and the hedonic component, for girls only $(\rho=.26, p=.001)$.

The subjective well-being of children

The responses study participants gave to items on the PWI-SC are shown in descending order in Table 2.

Insert Table 2 about here

As Table 2 shows, the items of satisfaction which received the highest mean score were "getting on with the people you know" and satisfaction "with your health" (the mean was higher than 9 for both). The overall mean score on the PWI-SC on a scale of 0 to 100 was 86.54 (SD = 10.54).

In keeping with the recommendations of the tool's authors, the index was recalculated, excluding the 29 subjects who gave extreme responses to all questions (responses of 0 or 10 ), resulting in a mean score of $85.25(S D=10.17)$. As there were no statistically significant differences between the two means, this study continued to utilize the data from all respondents.

There were no statistically significant differences with regard to gender for the PWI-SC index, but there were for the indicator "satisfaction with what may happen to you later in life" (t (365) = 2.206, $p=.0 .028$ (two-tailed), $\eta=.115)$, girls $(M=8.50 ; S D=2.01)$ being the ones with the higher mean score compared to boys $(M=8.03 ; S D=2.11)$. 
The OLS score $(M=9.09, S D=1.54)$ and satisfaction scores for other complementary life domains are high (means range from 8.62 to 9.71 ). The highest mean corresponded to satisfaction "with your family," while the lowest corresponded to satisfaction "with food" (see Table 3). There were no statistically significant differences with regard to gender for OLS or any of the items described in Table 3.

\section{Insert Table 3 about here}

\section{Food and well-being}

The correlation between interest in food and the PWI-SC was significant yet moderate $(\rho=.38$, $p<.001$ ). Correlations were similar for both genders (girls: $\rho=.38, p<.001 ;$ boys: $\rho=.35, p<$ $.001)$.

Correlations were lowest between interest in food and OLS and other indicators of satisfaction which are not included on the PWI-SC, presented in Table 4.

Insert Table 4 about here

The highest correlation for boys was with satisfaction "with your body" $(\rho=.22, p=.001)$, while the highest correlation for girls was for satisfaction "with the sports you play" $(\rho=.30, p<.001)$. The lowest correlations were satisfaction "with your family" for boys $(\rho=.15, p=.03)$ and satisfaction "with your friends" for girls $(\rho=.17, p=0.28)$.

The three principal components encapsulating the degree of importance which participants attributed to different components when it comes to eating (health, hedonism, and social influence) reflected statistically significant correlations with the PWI-SC, although these correlations are not particularly strong (health component: $\rho=.34, p<.001$; hedonic component: $\rho=.27, p<.001$; social influence component: $\rho=.19, p<.001)$.

Correlations between the PWI-SC and the 3 aforementioned components varied according to gender: for girls, the PWI-SC only showed a statistically significant positive correlation for the health component $(\rho=.26, p=.001)$ and the hedonic component $(\rho=.25, p=.002)$, while 
statistically significant positive correlations were found for all three components in boys (health: $\rho=.38, p<.001$; hedonic: $\rho=.29, p<.0001$; social influence: $\rho=.28, p=.002$ ).

The strongest correlation between the 3 components (health, hedonism, and social influence) and OLS were found in the importance given to questions of health. Only satisfaction "with your body" correlates with the three components (see Table 5).

Insert Table 5 about here

OLS correlates positively although modestly with the health component (girls: $\rho=.21, p=$ .008 , boys: $\rho=.27, p<.001$ ) and with the hedonic component, though in this case only for girls $(\rho=.21, p=.008)$.

The highest correlation for both boys and girls was found between the health component and the indicator entitled satisfaction "with your body" $(\rho=.24, p=.002$ and $\rho=.24, p=.001$, respectively).There were statistically significant correlations between the hedonic component and satisfaction "with your friends" $(\rho=.22, p=.006)$, and "with your family" $(\rho=.16, p=.048)$, again only for girls.

After conducting the analyses described above, a series of regression models were run using the stepwise method in order to gain additional insight into the relationships between indicators related to food and personal well-being, using "satisfaction with food" (SATFOOD) as the link between these two constructs.

An analysis of SATFOOD results in terms of the three principal components classifying eatingrelated motivations and interest in food revealed that the model was significant (Adjusted $R^{2}=$ $.25, F(2.339)=56.47, p<.001)$. As Table 6 shows, the health component and interest in food appear as significant predictors when it comes to explaining SATFOOD.

\section{Insert Table 6 about here.}

Running this model with responses from only boys and then only girls revealed that for girls (Adjusted $\left.\mathrm{R}^{2}=.31 . \mathrm{F}(2.157)=36.37, \mathrm{p}<.001\right)$ the variable which best explained the SATFOOD 
scores was the health component, followed by the hedonic component, whereas for boys (Adjusted $\left.\mathrm{R}^{2}=.23 . \mathrm{F}(2.181)=27.92, \mathrm{p}<.001\right)$ the variable reflecting the highest beta value was interest in food, followed by the health component.

In order to explore which subjective well-being indicators act as predictors for SATFOOD we ran additional regression models with the OLS and the PWI-SC separately.

Both models are significant (OLS: Adjusted $R^{2}=.21 . F(1.368)=102.331, p<.001$ (Table 7); PWI-SC: Adjusted $\left.\mathrm{R}^{2}=.22 . \mathrm{F}(4.356)=26.363, \mathrm{p}<.001\right)$. Only 4 domains of the PWI-SC explain SATFOOD (see Table 8).

Insert Table 7 about here.

Insert Table 8 about here.

The results show that the only two domains with a statistically significant beta value are "health" and "the things you want to be good at" in the girls model (Adjusted $R^{2}=.22 . F(2.166)=24.91$, $\mathrm{p}<.001$ ), whereas the model for boys included "health", "getting on with the people you know", "doing things away from your home" and "what may happen to you later in life", and in decreasing order (Adjusted $\mathrm{R}^{2}=.27 . \mathrm{F}(4.189)=18.80, \mathrm{p}<.001$ ).

The degree to which complementary indicators of life satisfaction contribute to predicting SATFOOD values was explored through a linear regression model. The model revealed that all of the aforementioned indicators made a significant contribution, with the exception of satisfaction "with the sports you play" (Adjusted $R^{2}=.21$. F $(3.361=32.45, p<.001)$ (see Table $9)$.

Insert Table 9 about here.

The beta values suggest that the predictor to best explain SATFOOD in the model described in Table 9 is satisfaction "with your body", while the variable to least explain it is "your friends". Subsequently, the same model was run separately for both boys and girls. The only predictor 
for girls (Adjusted $R^{2}=.18 . F(1.168)=39.25, p<.001$ ) was satisfaction "with your body," By contrast, results for boys (Adjusted $\mathrm{R}^{2}=.25 \mathrm{~F}(3.192)=31.12, \mathrm{p}<.001$ ) showed that the predictor with the highest beta value was satisfaction "with your body," followed by satisfaction "the sports you play" and "with your family".

Finally, in order to analyze which indicators are significant in the above partial models when grouped together, we calculated a last linear regression model to explain SATFOOD. It is observed that this model includes 4 predictors, OLS being the indicator with the highest contribution (Adjusted $\left.\mathrm{R}^{2}=.41 . \mathrm{F}(4,328)=58.29, \mathrm{p}<.001\right)$ (Table 10).

Insert Table 10 about here.

The indicators with the highest explanatory capacity for SATFOOD using this model, after OLS, are the health component, "satisfaction with health" from the PWI-SC and "satisfaction with doing things away from home", for both genders, "satisfaction with your body" (Adjusted $R^{2}=$ .43. $F(4.153)=29.41, p<.001)$ in the model for girls only and OLS and satisfaction with doing things away from home and satisfaction with family (Adjusted $R^{2}=.45 . F(4.174)=37.49, p<$ .001 ) in the model for boys only (Table 11).

Insert Table 11 about here.

\section{DISCUSSION}

The children who took part in this study displayed a high level of interest in food-related issues. Although there are no data to demonstrate it categorically, we believe that this keen interest could be attributed to the effectiveness of the various strategies implemented in Spanish schools to raise awareness about and promote healthy lifestyles among the child population (namely the Strategy for Nutrition, Physical Activity and the Prevention of Obesity, Agencia Española de Seguridad Alimentaria y Nutrición 2005), and the Integral Plan for Health Promotion through Physical Activity and Healthy Eating (Departament de Salut de la Generalitat de Catalunya 2005b). In order to test this hypothesis, it would be necessary to evaluate the 
impact of this kind of program on children by measuring their interest in food-related issues before and after the implementation of the specific program. Motivations for the sample children's food choices coincide with the results obtained by De Moura (2007), with sensory factors such as taste being the most prevalent factor, closely followed by health-related aspects. An analysis of the predominant reasons for children's evaluation of food reveals some differences between the genders. Girls prioritize feeling good after eating, unlike boys, who attach more importance than girls to eating things that they have seen in television advertisements.

Feeling good after eating has both a physical and a psychological dimension. The ingestion of healthy food may contribute to both dimensions, as it is easier to digest compared to nonhealthy food and it is one of the most important means of controlling weight, something very important for girls according to the reviewed literature. Food-related advertisements which have children and adolescents as the main target are generally for fatty and sugary foods like biscuits, snacks and soft drinks. This could be a plausible explanation for boys giving more importance than girls to eating things previously seen in advertisements, in that the existent literature points to their stronger preference for this kind of food. To understand the source of these differences, however, it will be necessary in the future to apply qualitative methodology techniques such as in-depth personal interviews or focus groups.

The importance of the component of "health" as an indicator of motivations influencing food choices, widely recognized among the adult population (Neumark-Sztainer et al. 1999), is also apparent in our results, demonstrating the extent to which the children surveyed are conscious of the link between food and health. This finding supports the claims of authors such as Contento (2007), who argues that it is during preadolescence that children start to become aware of the consequences of their actions in relation to what they eat.

As far as motivations for eating are concerned, the lowest means correspond to variables related to an external influence factor such as, for example, foods having been seen in advertisements. This contrasts with previous studies that suggest that children are particularly 
vulnerable to the influence of advertisements with respect to their eating habits (Mehta et al. 2010; Medeiros et al. 2008).

In line with the results obtained by De Moura (2007), the children in our sample who are most interested in food are those whose eating preferences are most influenced by health-related issues. The fact that girls of this age display a positive correlation between interest in food and a component of hedonic motivation for eating while boys do not is a phenomenon which would be worth studying in the future. The correlation between the factor of external influences and interest in food is weak and statistically insignificant.

The subjective well-being of children under 12 is an issue which has hardly been addressed in the literature owing to the difficulty involved in using concepts that are somewhat abstract in nature. We studied this notion by using an adapted version of the Personal Well-being Index (Cummins \& Lau 2005) to facilitate comprehension among the sample group of Catalan children.

The mean PWI-SC index scores for the children surveyed show that they have high levels of well-being, corroborating the positive opinions about their lives as a whole expressed by many children and teenagers in other research (Tomyn \& and Cummins 2011). The results obtained in our study are slightly higher and contain less variability of responses than the normative values defined by the authors for the Australian population $(M=75, S D=12.65$; Cummins \& Lau 2005). This difference could be due to factors such as the size of the sample. It could also be attributed to the different sociocultural context involved. To verify this hypothesis, this study would have to be extended to include larger samples. Another hypothesis worth exploring in greater detail in the future, and one which we would particularly like to emphasize, is that normative values for the Australian population may be higher for the child population than for the adolescent and adult population.

In a previous study (González et al. 2012) based on a sample of adolescent and young adults (15-24 years old) regarding their personal well-being (using the adult version of the Personal Well-being Index by Cummins and Lau (2006)), differences were found according to the gender 
of the participants. Contrarily, in our study there are no significant differences between boys and girls for the whole PWI-SC, but there is in relation to one specific domain "satisfaction with what may happen to you in later life", with girls scoring higher. This same result was found in the study by Tomyn \& Cummins (2011) using the same index (PWI-SC), but applied to 351 students aged 12 to 20 .

The life satisfaction domain to obtain the highest mean from the PWI-SC was "having good relationships with other people", which the children displayed a high awareness of, demonstrating the importance of interpersonal relationships and presumably the social support children receive from parents, classmates, teachers and close friends (Demaray \& Malecki 2002; Casas, 2010; Goswami 2011).

The next most important domain (according to the mean scores obtained) is health, indicating that this is a prominent life concern among the child population. One of the domains to produce a low mean was security for future. A similar trend was observed with samples of teenagers and young people aged 15 to 24 (González et al. 2012), and this result could be attributed to a heightened sense of uncertainty when thinking about the future. In light of this consideration, subsequent questionnaires might designate a specific period in the future (3 years, for example) to make it easier for participants from these age groups to respond.

As for OLS and satisfaction with other specific life domains studied in parallel to the PWI-SC, the importance of interpersonal relationships is again borne out by the respondents' answers concerning "satisfaction with family" and "satisfaction with friends", with these domains obtaining the highest scores. Both boys and girls scored high on OLS, and they were "satisfied with their body" as well as "with food", although the mean score for these specific aspects is slightly lower than the figures for "satisfaction with family" and "satisfaction with friends".

There are correlations, albeit moderate ones, between interest in food and the PWI-SC and between the three components of food motivations and the PWI-SC - for both boys and girls. The fact that correlations are only moderate might be due to the fact that none of the PWI-SC 
indicators explicitly refer to something as specific as food, given that they are constructed on a higher level of abstraction.

Correlations between this interest in food and OLS and complementary domains of satisfaction explored alongside the PWI-SC are statistically significant yet weak, with the closest correspondence coming between interest and OLS. Boys and girls exhibit a different pattern of responses, to the extent that the strongest correlation in the case of girls relates to interest and "satisfaction with the sports you play", while for boys it is interest and "satisfaction with your body", suggesting different roots for their respective interest in food.

In this paper, SATFOOD has been understood as an element that allows us to evaluate those aspects that can help children enjoy their food and bring them to consider it as a pleasurable and important element for their well-being and quality of life. It is worth mentioning that the indicators that explain SATFOOD are not the same for boys and girls. Further studies are needed in order to analyze the reasons for such differences in more depth.

From the regression models we have run, we see that SATFOOD is explained through both food indicators and well-being indicators. These findings justify the consideration of SATFOOD as a variable for evaluating elements related to food (health motivations) and others related to well-being (satisfaction with health and with doing things away from home, from the PWI-SC, and the OLS) for the children participating in this study. The fact that satisfaction with doing things away from home contributes to explaining SATFOOD may have to do with eating out in a bar or restaurant, something which children aged 10 to 12 probably enjoy doing with their families. The data obtained in this paper do not allow this hypothesis to be tested, however.

The results obtained suggest that adults are probably underestimating the role played by food in the lives of children aged between 10 and 12, with this issue having long been considered solely of interest to adults or, at most, to older children. This statement is based on the fact that there are more studies carried out on adults than on children and, of the latter, only very few on young children. 
It is important to understand how eating practices are conditioned from a young age and what affects this in order to be able to devise tools that help promote a more suitable dietary education for different groups, one that would bear in mind similarities and differences between each age bracket. There is a need to explore the role of indicators such as satisfaction with food, young people's interest in food, and the child population's levels of subjective well-being in order to open up new avenues of research in the field of health education and promotion. To achieve this goal, future research must be carried out in which a prominent role is afforded to children's perspectives, which will allow us to be able to look in greater depth at the connections between this population group's subjective well-being and satisfaction with food.

Children's well-being includes the evaluations and aspirations of children themselves, while considering them active social actors who can reliably explain the experiences and meanings constituting their well-being.

It is important to point out some of the limitations of the study presented in this article. The sample used comprised schools that expressed an interest in taking part in the study. There is no way of knowing whether the sample is somehow skewed with respect to the rest of the schools in the region of Osona. It is possible that the schools not involved might exhibit distinctive characteristics in relation to the variables explored in this article. Ideally, future studies would collect data from a larger pool of schools.

The cross-sectional approach adopted in this study limits our ability to comprehend how the variables studied change over time. In other words, whether the children who are satisfied at present cease to be so over time or whether their well-being varies as a result of changes in the importance of food in their lives. It would be necessary to carry out a longitudinal study to examine this evolution.

Finally, it is worth contemplating the possible value of applying qualitative methodologies (such as discussion groups) in future studies in order to be able to investigate the different aspects discussed in this article in greater depth, as well as considering further work on the promotion of healthy eating habits based on the levels of interest in food shown in this study. This could 
serve as a starting point to improve children's motivation and participation with respect to both developing healthy practices initially promoted at a young age and maintaining them throughout adolescence, thereby fostering good eating habits.

\section{ACKNOWLEDGMENTS}

Support for the collection of data used in this article was provided by the Health Protection Agency of Osona, the Government of Catalonia's Department of Health, and the University of Vic. Comments by Enrico Bignetti have contributed enormously to improving the paper. Particular thanks are due to Barney Griffiths for editing English.

\section{REFERENCES}

Agencia Española de Seguridad Alimentaria y Nutrición (2005). Estrategia para la nutrición, actividad física y prevención de la obesidad (NAOS). Resource document. Ministerio de Sanidad y Consumo de España. http://www.naos.aesan.msps.es. Accessed 25 June 2011.

Aranceta, J. (1995). Nutrición en la edad evolutiva. In Serra, Ll., Aranceta, J., \& Mataix, J., Nutrición y Salud Pública. Métodos, bases científicas y aplicaciones (2nd ed., 185-192). Barcelona, Spain: Masson.

Aranceta, J., Pérez, C., Serra, LI., \& Delgado, A. (2004). Hábitos alimentarios de losalumnos usuarios de comedores escolares en España. Estudio "Dime Cómo Comes". Atención Primaria, 33(3),131-139.

Campbell, A., Converse, P., \& Rodgers, W. (1976). The quality of American life: Perceptions, evalutations and satisfactions. New York: Russel Sage Fountadion.

Casas, F. (2010). Subjective social indicators and child and adolescent well-being. Child Indicators Research. DOI 10.1007/s1287-010-9093-z.

Contento, I. (2007). Nutrition education, linking research, theory and practice. EUA:Jones and Bartlett Publishers. 
Enhancingpersonal agency and competence in eating and moving: Formative evaluation of a middle school curriculum. Choice, control and change. Journal of Nutrition Education Behaviour, 39(S5), 179S-186S.

Cooke, L., \& Wardle, J.(2005). Age and gender differences in children's food preferences. British Journal of Nutrition, 93, 741-746.

Cummins, R. A. (2003). Normative life satisfaction: Measurement issues and a homeostatic model. Social Indicators Research, 64, 225-256.

Cummins, R. A. (1998). The second approximation to an international standard of lifesatisfaction. Social Indicators Research, 43, 307-334.

Cummins, R. A., Eckersley, R., Van Pallant, J., Vugt, J., \& Misajon, R. (2003). Developing a national index of subjective well-being: The Australian Unity Well-being Index. Social Indicators Research, 64, 159-190.

Cummins, R A., \& Lau, A. (2006). Manual: personal well-being index - adult. Fourth edition. Resource document. Melbourne: Australian Centre on Quality of Life, Deakin University. http://www.deakin.edu.au/research/acqol/instruments/well-being-index/pwi-adult-english.pdf. Accessed 29 August 2011.

Cummins, R A., \& Lau, A. (2005). Manual: personal well-being index - school children. Third edition. Resource document. Melbourne: Australian Centre on Quality of Life, Deakin University. http://www.deakin.edu.au/research/acqol/auwbi/index-translations/wbi-schoolenglish.pdf. Accessed 29 August 2011.

Cummins, R A., \& Lau, A. (2004). Manual: personal well-being index - pre -school children. Second edition. Resource document. Melbourne: Australian Centre on Quality of Life, Deakin University. http://www.deakin.edu.au/research/acqol/instruments/well-being-index/. Accessed 29 August 2011.

Demaray, M., \& Malecki, C. (2002). The relationship between perceived social support and maladjustment for students at risk. Psychology in the Schools, 39(3), 305-316.

De Moura, S. L. (2007). Determinants of food rejection amongst school children. Appetite, 49, 716-719. 
Departament de Salut de la Generalitat de Catalunya (2005a). Guia de l'alimentació saludable en l'edat escolar. Resource document. Departament d'educació i Departament de salut de la Generalitat de Catalunya.

http://www10.gencat.cat/gencat/binaris/guia alimentacio escola tcm32-25805.pdf. Accessed 15 June 2011.

Departament de Salut de la Generalitat de Catalunya (2005b). Pla integral per a la Promoció de la salut mitjançant l'Activitat física i l'Alimentació Saludable (PAAS). Resource document. Generalitat de Catalunya. http://www.gencat.cat/salut/depsalut/pdf/paas.pdf . Accessed 15 June 2011.

Eid. M, \& Diener, E. (2004). Global judgments of subjective well-being: Situational variability and long-terms stability. Social Indicators Research, 65, 245-277.

González, M., Casas, F., Malo, S., \& Viñas, F. (2012). Satisfaction with present safety and future security as components of personal well-being among young people: relationships with other psychosocial constructs. In Webb. D. \& Wills-Herrera, E. (ed.). Subjective Well-Being and Security. 46. 253-290. Social Indicators Research Series.

Goswami, H. (2011). Social relationships and children's subjective well-being. Social Indicators Research. DOI 10.1007/s11205-011-9864-z.

Mavrommatis, Y., Moynihan, P. J., Gosney, M. A., \& Methven, L. (2011). Hospital catering systems and their impact on the sensorial profile of foods provided to older patients in the UK. Appetite, 57, 14-20.

Medeiros, G., Amboni, R., \& Teixeira, E. (2008). Television use and food choices of children: Qualitative approach. Appetite, 50, 12-18.

Mehta, K., Coveney, J., Ward, P., Magarey, A., Spurrier, N., \& Udell, T. (2010). Australian children's views about food advertising on television. Appetite, 55, 44-55.

Neumark, D., Story, M., Perry, C., \& Cassey, M. (1999). Factors influencing food choices of adolescents: Findings from focus-group discussions with adolescents. Journal of The American Dietetic Association, 99(8), 929-937.

Serra, LL., Ribas, L., García, R., Pérez, C., Peña, C., \& Aranceta, J. (2002). Hábitos 
alimentarios y consumo de alimentos en la población infantil y juvenil española (1998-2000): variables socioeconómicas y geográficas. In Serra, LI., \& Aranceta, J. Alimentación infantil y juvenil: Estudio EnKid (3, 13-19). Barcelona, Spain: Editorial Masson.

Pich, J., Ballester, LI., Thomàs, M., Canals, R., Tur, J. (2010). Assimilating and following through with nutritional recommendations by adolescents. DOI: 10.1177/0017896910379695

Proctor, C., Linely, P., \& Maltby, J. (2009). Youth life satisfaction: A review of the literature. Journal of happiness studies, 10, 586-630. DOI 10.1007s/10902-008-9110-9.

Tomyn, A., \& Cummins, R. (2011). The subjective well-being of high-school students: Validating the personal well-being index-school children. Social Indicators Research, 3(101), 405-418.

Tomyn, A., Norrish, J., \& Cummins, R. (2011). The subjective wellbeing of indigenous Australian adolescents: Validating the personal wellbeing index-school children. Social Indicators Research. DOI 10.1007/s11205-011-9970-y.

Valois, R., Zulling, K., Huebner, S., \& Wanzer, D. (2003). Dieting behaviors. Weight perceptions, and life satisfaction among public high school adolescents. Eating disorders, 11, 271-288.

Watters, C., Sorensen J., Fiala A., \& Wismer, W. (2003). Exploring patient satisfaction with foodservice through focus groups and meal rounds. Journal of the American Dietetic Association, 103, 1347-1349. 
Figure 1 Importance given to different indicators for food decision-making

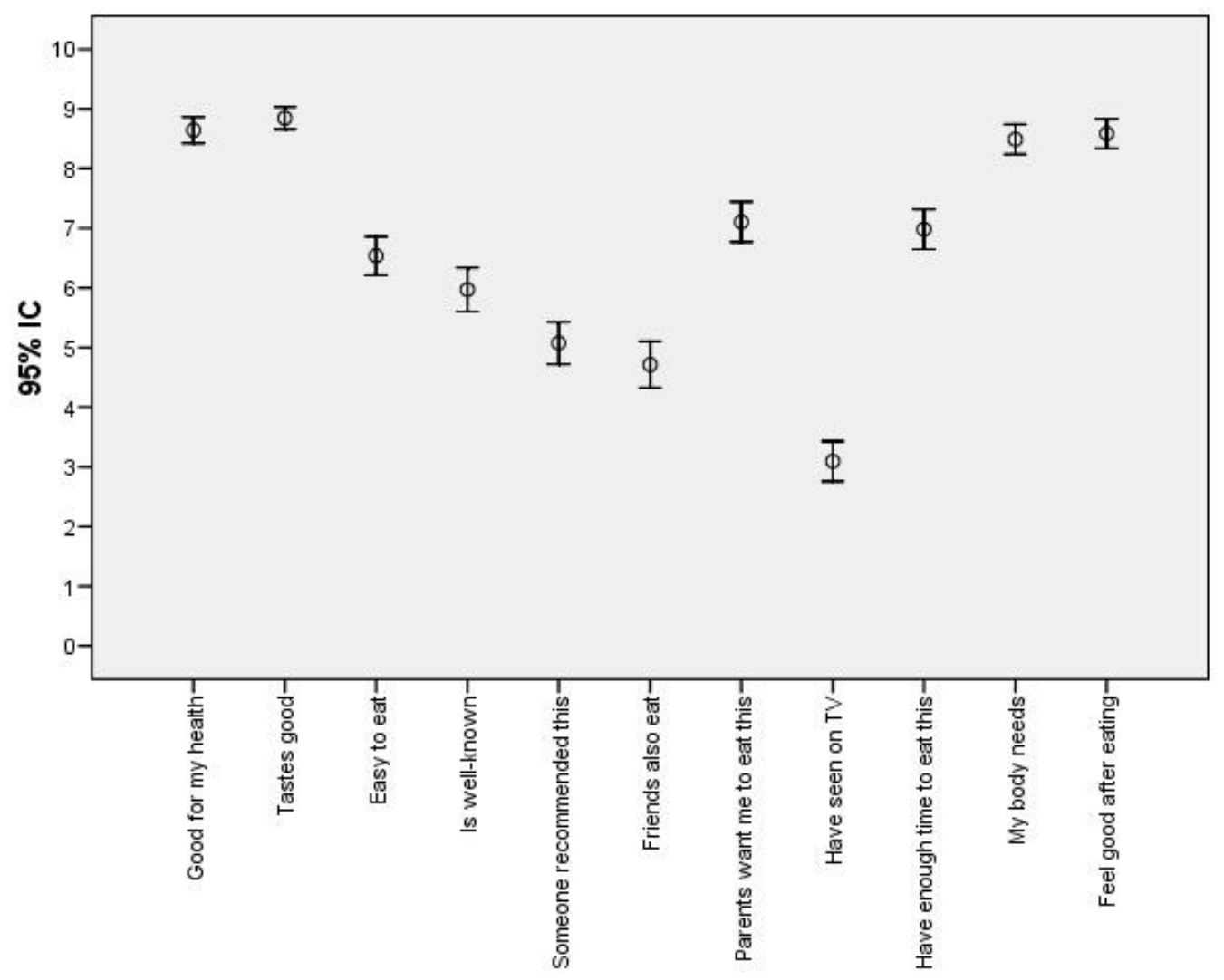


Table 1 Principal component analysis (PCA): Rotated component matrix of the different indicators related to food decision-making (loadings below .2 are not displayed)

\begin{tabular}{|c|c|c|c|}
\hline & $\begin{array}{l}\text { Component 1: } \\
\text { Social Influence }\end{array}$ & $\begin{array}{l}\text { Component 2: } \\
\text { Health }\end{array}$ & $\begin{array}{l}\text { Component 3: } \\
\text { Hedonic }\end{array}$ \\
\hline I have seen this food on TV & .768 & & \\
\hline My friends also eat this food & .743 & & \\
\hline Someone recommended this food to me & .680 & .252 & \\
\hline This food is well-known & .647 & & .240 \\
\hline I have enough time to eat this food & .389 & .245 & \\
\hline My body needs this food & & .843 & \\
\hline My parents want me to eat this food & & .703 & \\
\hline This food is good for my health & .266 & .694 & \\
\hline This food makes me feel comfortable & .303 & .555 & \\
\hline This food tastes good & & & .937 \\
\hline Eigenvalues & 3.068 & 1.484 & 1.027 \\
\hline Variance explained & 23.55 & 21.60 & 10.66 \\
\hline Cumulative variance & 23.55 & 45.14 & 55.80 \\
\hline Alpha & 0.622 & 0.694 & 0 \\
\hline
\end{tabular}

Correlation matrix determinant: 0.140

Kaiser-Meyer-Olkin measure of sampling adequacy: 0.763

Bartlett's test of sphericity: $\chi^{2}=667.173,45 ; p<.001$ 
Table 2 Means and standard deviations of items from the PWI-SC

\begin{tabular}{lcc}
\hline Satisfaction... & Mean & SD \\
\hline With getting on with the people you know & 9.23 & 1.46 \\
& & \\
\hline With your health & 9.19 & 1.45 \\
& & \\
\hline With the things you have & 8.69 & 1.78 \\
& & \\
\hline With the things you want to be good at & 8.55 & 1.80 \\
& & \\
\hline With how safe you feel & 8.46 & 1.80 \\
& & \\
\hline With what may happen to you later in life & 8.25 & 2.07 \\
& & \\
\hline With doing things away from your home & 8.11 & 2.19 \\
& & \\
\hline
\end{tabular}

Table 3 Means and standard deviations for complementary satisfaction with life domains explored

\begin{tabular}{lcc}
\hline Satisfaction... & Mean & SD \\
\hline With your family & 9.71 & 1.00 \\
\hline With your friends & 9.26 & 1.59 \\
& & \\
\hline With the sports you play & 8.86 & 2.18 \\
\hline With your body & & \\
\hline With food & 8.77 & 1.83 \\
& & \\
\hline
\end{tabular}


Table 4 Spearman correlations between interest in food, satisfaction with the other life domains explored and OLS

\begin{tabular}{lc}
\hline Satisfaction... & Interest in food \\
\hline With your friends & $.13, \mathrm{p}=.015$ \\
\hline With your family & $.14, \mathrm{p}=.008$ \\
\hline With the sports you play & $.18, \mathrm{p}=.001$ \\
\hline With your body & $.23^{*}$ \\
\hline OLS & $.28^{*}$ \\
\hline * Significant difference, $\mathrm{p}<0.001$
\end{tabular}

Table 5 Spearman correlations between the three components identified in the PCA with OLS and other satisfaction with life domains

\begin{tabular}{|c|c|c|c|}
\hline Satisfaction... & $\begin{array}{l}\text { Health } \\
\text { Component }\end{array}$ & $\begin{array}{l}\text { Hedonic } \\
\text { Component }\end{array}$ & $\begin{array}{l}\text { Social influence } \\
\text { Component }\end{array}$ \\
\hline With your friends & $.16, p=.003$ & $.16, p=.003$ & - \\
\hline With your family & $.22^{*}$ & $.12, p=.039$ & - \\
\hline With the sports you play & $.23^{*}$ & $.11, p=.038$ & - \\
\hline With your body & $.24^{*}$ & $.14, p=.008$ & $.12, p=.025$ \\
\hline OLS & $.25^{\star}$ & $.14, p=.010$ & - \\
\hline
\end{tabular}


Table 6 Linear regression of the three components related to food decision-making and interest in food on Satisfaction with food

\begin{tabular}{|c|c|c|c|c|c|}
\hline & \multirow[t]{2}{*}{$\beta$} & \multirow[t]{2}{*}{$\bar{t}$} & \multirow[t]{2}{*}{ Sig. } & \multicolumn{2}{|c|}{ Confidence interval of $95 \%$} \\
\hline & & & & Lower limit & Upper limit \\
\hline Health & .37 & 7.70 & $p<.001$ & .499 & .842 \\
\hline Component & & & & & \\
\hline Interest in food & .25 & 5.10 & $\mathrm{p}<.001$ & .111 & .250 \\
\hline
\end{tabular}

Table 7 Linear regression of OLS on Satisfaction with food

\begin{tabular}{lccccc}
\hline & $\beta$ & $\mathbf{t}$ & Sig. & \multicolumn{2}{c}{ Confidence interval of 95\% } \\
& & & Lower límit & Upper limit \\
\hline OLS & .47 & 10.12 & $\mathrm{p}<.001$ & .438 & .650 \\
\hline
\end{tabular}

Table 8 Linear regression of PWI-SC domains on Satisfaction with food

\begin{tabular}{|c|c|c|c|c|c|}
\hline & $\beta$ & $\mathbf{t}$ & Sig. & Confidence & erval of $95 \%$ \\
\hline & & & & Lower límit & Upper limit \\
\hline Satisfaction with health & .31 & 6.20 & $\mathrm{p}<.001$ & .260 & .502 \\
\hline With doing things away from your home & .15 & 3.05 & $p=.002$ & .043 & .198 \\
\hline With the things you want to be good at & .14 & 2.74 & $p=.006$ & .037 & .227 \\
\hline With what may happen to you later in life & .12 & 2.42 & $p=.016$ & .019 & .180 \\
\hline
\end{tabular}


Table 9 Linear regression of other satisfaction with life domains on Satisfaction with food

\begin{tabular}{llllcc}
\hline Satisfaction with... & $\boldsymbol{\beta}$ & $\mathbf{t}$ & $\mathbf{S i g}$ & \multicolumn{2}{c}{ Confidence interval (95\%) } \\
& & & & Lower límit & Upper limit \\
\hline With your body & .36 & 7.44 & $\mathrm{p}<.001$ & .256 & .440 \\
\hline With your family & .17 & 3.44 & $\mathrm{p}=.001$ & .132 & .482 \\
\hline With your friends & .11 & & & & .014 \\
\end{tabular}

Table 10 Final linear regression of previous statistically significant indicators on Satisfaction with food

\begin{tabular}{|c|c|c|c|c|c|}
\hline & $\beta$ & $\mathbf{t}$ & Sig. & Confidence & terval (95\%) \\
\hline & & & & Lower límit & Upper limit \\
\hline OLS & .34 & 7.32 & $p<.001$ & .304 & .531 \\
\hline Health Component & .29 & 6.41 & $p<.001$ & .354 & .667 \\
\hline Satisfaction with your health (PWI-SC) & .19 & 4.03 & $p<.001$ & .126 & .366 \\
\hline $\begin{array}{l}\text { Satisfaction with doing things away from } \\
\text { home (PWI-SC) }\end{array}$ & .11 & 2.35 & $p=.019$ & .014 & .160 \\
\hline
\end{tabular}


9

$$
10
$$$$
11
$$$$
12
$$$$
13
$$$$
14
$$$$
15
$$$$
16
$$$$
17
$$$$
18
$$$$
19
$$$$
20
$$$$
21
$$$$
22
$$$$
23
$$$$
24
$$$$
25
$$$$
26
$$$$
27
$$$$
28
$$$$
29
$$$$
30 \text { home (PWI-SC) }
$$$$
31
$$$$
32
$$$$
33
$$$$
34
$$$$
35
$$$$
36
$$$$
37
$$$$
38
$$$$
39
$$$$
40
$$$$
41
$$$$
42
$$$$
43
$$

Table 11 Final linear regression of previous statistically significant indicators on Satisfaction

\begin{tabular}{|c|c|c|c|c|c|}
\hline \multirow[t]{2}{*}{ Girls } & \multirow[t]{2}{*}{$\beta$} & \multirow[t]{2}{*}{$\mathbf{t}$} & \multirow[t]{2}{*}{ Sig. } & \multicolumn{2}{|c|}{ Confidence interval (95\%) } \\
\hline & & & & Lower limit & Upper limit \\
\hline Health Component & 0.39 & 5.80 & $p<.001$ & .479 & .974 \\
\hline Satisfaction with your health (PWI-SC) & 0.21 & 3.04 & $p=.003$ & .097 & .458 \\
\hline Satisfaction with your body & 0.18 & 2.45 & $p=.015$ & .034 & .314 \\
\hline Boys & & & & & \\
\hline OLS & 0.44 & 6.90 & $p<.001$ & .351 & .631 \\
\hline Health Component & 0.24 & 4.16 & $\mathrm{p}<.001$ & .209 & .587 \\
\hline Satisfaction with doing things away from & 0.17 & 2.78 & $p=.006$ & .041 & .240 \\
\hline Satisfaction with your family & 0.15 & 2.64 & $p=.0009$ & .097 & .671 \\
\hline
\end{tabular}

with food by gender

\section{irls}

(1) 